\title{
Ab Initio Calculations and Raman and SERS Spectral Analyses of Amphetamine Species
}

Berg, Rolf W.; Nørbygaard, Thomas; White, Peter C.; Abdali, Salim

Published in:

Applied Spectroscopy Reviews

Link to article, DOI:

$10.1080 / 05704928.2010 .520180$

Publication date:

2011

Link back to DTU Orbit

Citation (APA):

Berg, R. W., Nørbygaard, T., White, P. C., \& Abdali, S. (2011). Ab Initio Calculations and Raman and SERS Spectral Analyses of Amphetamine Species. Applied Spectroscopy Reviews, 46(2), 107-131.

https://doi.org/10.1080/05704928.2010.520180

\section{General rights}

Copyright and moral rights for the publications made accessible in the public portal are retained by the authors and/or other copyright owners and it is a condition of accessing publications that users recognise and abide by the legal requirements associated with these rights.

- Users may download and print one copy of any publication from the public portal for the purpose of private study or research.

- You may not further distribute the material or use it for any profit-making activity or commercial gain

- You may freely distribute the URL identifying the publication in the public portal

If you believe that this document breaches copyright please contact us providing details, and we will remove access to the work immediately and investigate your claim. 


\title{
$A b$ Initio Calculations, Raman and SERS Spectral Analyses of Amphetamine Species
}

\author{
Rolf W. Berg ${ }^{a, *}$, Thomas Nørbygaard ${ }^{b}$, Peter C. White ${ }^{c}$ and Salim Abdali ${ }^{\text {i }}$ \\ aDepartment of Chemistry, Technical University of Denmark, \\ Kemitorvet, Building 207, DK-2800 Lyngby, Denmark. rwb@kemi.dtu.dk \\ $+45-40504191$ \\ ${ }^{b}$ GI. Lyngevej 82, DK-3450 Allerød, Denmark. thomas@nrbygaard.dk \\ $+45-61606197$ \\ ${ }^{\mathrm{C}}$ ReForensics, PO Box 1208, Lincoln, LN5 5LT, UK. Lyric29P@aol.com \\ $+44-7711331418$ \\ ${ }^{\mathrm{d} D e p a r t m e n t}$ for Molecular Cancer Biology, Danish Cancer Society, \\ Strandboulevarden 49, DK-2100 Copenhagen $\varnothing$, Denmark. abdali@cancer.dk \\ $+45-42455445$
}

* Corresponding author: Rolf W. Berg (rwb@kemi.dtu.dk)

Key Words: Spectroscopy, amphetamine, ab initio calculation, conformation, molecular orbital, Raman, IR, SERS, identification, drugs, forensic.

\begin{abstract}
For the first time, the differences between the spectra of amphetamine and amphetamine- $\mathrm{H}^{+}$, and between different conformers are thoroughly studied by ab initio model calculations, and Raman and SERS spectra are measured for different species of amphetamine. The spectra of amphetamine and amphetamine- $\mathrm{H}^{+}$samples were obtained and assigned according to a comparison of the experimental spectra and the ab initio MO calculations, performed using the Gaussian 03W program. The analyses were based on complete geometry minimisation of the conformational energy of the S-plus-amphetamine molecule and the S-plus-amphetamine- $\mathrm{H}^{+}$ ion. The harmonic frequency calculations provide information about the characteristic features of the Raman spectra and the nature of the bonding in the molecule. It is concluded that vibrational bands from salt anions with internal bonds (sulfates, hydrogen phosphates, etc.) need to be taken into account when employing these spectra for identification purposes. These results also show how Raman spectroscopy can assist the forensic community in drug profiling studies. Furthermore, as their spectra are different, discrimination between the free and protonated forms of amphetamine salts can be observed. Here, we provide evidence for this difference, and show experimentally, how it has been overseen.
\end{abstract}

\section{Introduction}


Amphetamine, $\mathrm{C}_{9} \mathrm{H}_{13} \mathrm{~N}$, also called alfa-methyl-benzeneethaneamine, 1-phenyl-2-propanamine, beta-phenyl-isopropylamine or many other names, is the progenitor molecule among the amphetamines, a group of structurally related compounds with stimulating properties [1]. It is well-known for many years that amphetamines have been illegally used and have large potentials for abuse, addiction and toxicity [2]. Consequently, clandestine laboratories have been producing closely related substances to circumvent drug legislation [3]. Such compounds that are structurally related to amphetamine are referred to as designer drugs [4]. Customary, these compounds have most often been analysed by gas chromatography and mass spectrometry [3], [5], [6], [7].

In recent years, Raman Spectroscopy and Surface Enhanced Raman Spectroscopy (SERS) have proved to be powerful methods for determination of the composition profile of solid, liquid and gas samples [8] and for very low concentrations, e.g. below micromolar [9]. The two methods have also been applied to amphetamine, but a close look in the literature evidences confusion regarding different species. Here, we report a new Raman and SERS spectral study of amphetamine, assisted by ab initio calculations. We carried out this work partly because of the confusion among previously reported results, especially in differentiation between amphetamine itself and the chloride or sulfate solid salts because amphetamine is a weak base $\left(\mathrm{pK}_{\mathrm{a}}\right.$ is $\left.\sim 9.8\right)$, and thus can be protonated. The next section presents a literature review of the reported results. Spectral analysis and comparisons are also given to show the complexity of this molecule. Furthermore, identification of the provenance of the amphetamines is of considerable interest in forensic and legal cases. Medications on the market may contain varying amounts of the S-(+) and R-(-) forms of amphetamine, but since the circular dichroism of amphetamine is rather weak [7], Raman and SERS spectroscopy in combination with ab initio calculations should be of use as means of tracking the origin, and elucidate the difference that may arise due to the different racemic compositions of sample mixtures, which thus would vary depending on synthetic procedures used during preparation. We intend in a forthcoming study to employ chiral studies on this molecule by use of Raman optical activity assisted by $a b$ initio calculations.

\subsection{Historical Review}

During the last couple of decades, amphetamine compounds have been studied by Raman spectroscopy and recently also by SERS, aiming at discriminations between drug types and manufacturers. Already in 1978, the Raman spectrum of amphetamine sulphate, CAS No. [6013-9], using excitation with blue light (488 $\mathrm{nm})$, was published by Bass [10]. Hodges and Akhavan [11] in 1990 identified amphetamine sulfate in contaminated illicit drug samples by use of FT-Raman spectroscopy with near-IR excitation (1064 nm). Tsuchihashi and co-workes have shown a spectrum of amphetamine sulfate in their study [12]. These authors also used FTRaman spectroscopy and near-IR excitation $(1064 \mathrm{~nm})$ to reduce fluorescence problems they experienced when using a shorter excitation wavelength. Using this approach they succeeded in identifying methamphetamine ( $\mathrm{N}$-methylamphetamine) and related compounds down to a detection level of $1 \%$ (by weight) in sodium chloride, water and inside unopened polyethylene plastic bags. Bell et al. [13] used deep red light $(785 \mathrm{~nm})$ to excite Raman spectra directly from drug tablets, in order to identify N-methyl-3,4-methylenedioxyamphetamine and similar drugs. In their report [13], they claimed the measured spectra to be "amphetamine spectra", but the depicted spectra were probably those of (amphetamine- $\mathrm{H})_{2} \mathrm{SO}_{4}$ instead of amphetamine. Indeed they mentioned in their report [13] that the sample was a standard amphetamine sulfate, bought from Sigma-Aldrich Ltd., and their spectrum evidences the presence of sulfate Raman bands and this will be discussed later in our study. Other authors [14], also claimed determination of "amphetamine spectra", even though they also bought the sulfate and used it "as received", - and their spectra show sulfate bands (see later). Even Raman instrument 
manufacturers like Renishaw and Horiba-Jobin-Yvon in their forensic application notes have presented "amphetamine" spectra with sulfate bands".

Faulds et al. [15] reported the detection of amphetamine sulfate by SERS, using both silver and gold colloids on vapour deposited films, in an attempt to develop a methodology for the low level detection of amphetamine. They used thin aqueous solutions and - according to our interpretation - they probably detected amphetamine molecules or amphetammonium ions adsorbed on the surfaces, and they did not see any sulfate bands in their spectra. However, from their results one cannot conclude that there was no sulfate in the sample, as we have also found the same behaviour (we will discuss this in section 3.6). Day et al. [16], [17] have claimed to be able to distinguish between amphetamine sulfate and other drugs using Raman spectra of latent or cyanoacrylate-fumed fingerprints, sometimes after photo bleaching to reduce the fluorescence background. For this, they used deep red laser light $(785 \mathrm{~nm})$, but they did not report any spectra. Sägmüller et al. [18] have reported a method based on chromatography in combination with SERS to detect and identify amphetamine and other illicit drugs. For reference use, it should be mentioned that other authors [19], [20] have shown pre-resonance Raman and SERS spectra of the free amphetamine base. Sulk et al. [21] developed a procedure for derivatisation of amphetamine with 2-mercaptonicotinic acid to form an amide that could be detected and quantified by means of SERS spectra. Milhazes et al. [22] used Raman spectroscopy combined with ab initio calculations to characterise synthetic precursors of amphetamine-like drugs. Other detection possibilities can be found and are discussed in the literature [23]. Hargreaves et al. [24], [25] successfully identified d-amphetamine sulfate and other drugs in an airport environment using portable and bench top spectrometers, employing two different excitation wavelengths (785 and $1064 \mathrm{~nm}$ ). Katainen et al. [26] reported how they could quantify the amphetamine content in seized street samples by Raman spectroscopy, using an internal phosphate ion standard. The spectroscopic detection of amphetamine (and other common drugs of abuse) on textile fibres after recovering with adhesive lifters was demonstrated by West and Went [27].

With respect to quantum mechanical calculations on amphetamine-related molecules in various conformations, only a MP2/6-31G(d,p) level study has previously been reported [28], and this study did not include calculation of vibrational spectra.

This review of the literature seems to show that some confusion originates from the fact that in most forensic cases the form of the amphetamine samples is not so important because the drug is converted in the body. On the other hand, for spectroscopic detection it is important to have a precise knowledge of the nature of the drug or a precursor and relevant reference samples. Therefore, we performed this work to study, how the vibrational bands change, even disappear, by alterations of the acidity (or basicity) and the counter ions of the solution. Moreover, a combination of Raman, SERS and ab initio calculations were included to approach a better understanding of the spectra. Finally, to demonstrate the use of the Raman spectroscopy method we compared spectra of street drugs to a standard sample purchased from Sigma Aldrich.

\subsection{Nomenclature}

As commonly appreciated, the geometry of the amphetamine molecule (AMP, Fig. 1) is influenced by internal rotation around the C7-C8 bond, a degree of freedom which drastically alters the shape of the molecule. The geometry around the C8 atom is influenced by its four bonds to the $\mathrm{C} 7$ atom, the $\mathrm{C} 9$ atom, the amino group, and the $\mathrm{H}$ atom. To help in the presentation of our work, we introduce a ZX notation of the various conformers. The symbol ZX denotes the appearance of the $\mathrm{Ph}-\mathrm{C} 7-\mathrm{C} 8-\mathrm{X}$ skeleton, with the letter $\mathrm{Z}$ referring to the whole 
geometry, which - when seen from the side - looks somewhat like the letter $Z$ (as sketched in Fig. 1). The letter $X$ stands for an atom attached to $\mathrm{C} 8$, i.e. $\mathrm{N}, \mathrm{C} 9$ or $\mathrm{H}$, and thus the particular conformation isomer will be referred to as $\mathrm{ZN}, \mathrm{ZC}$ or $\mathrm{ZH}$, respectively. The different species are shown in Fig. 1 ( $a$ and $b$ for $A M P$ and $\mathrm{AMPH}^{+}$, respectively). The experimentally determined stereoisomer/conformational geometry for the sulfate (see later) hence will be denoted S-ZN in our notation, as the chirality of C8 is $\mathrm{S}$ and the atom attached to C8 to complete the letter $\mathrm{Z}$ is $\mathrm{N}$.

The crystal structure of the so-called D-(+)-amphetamine sulfate (or S-amphetamine sulfate, $\left(\mathrm{C}_{9} \mathrm{H}_{13} \mathrm{~N}\right)_{2} . \mathrm{H}_{2} \mathrm{SO}_{4}$, CAS No. [51-63-8]) has been determined by X-ray diffraction [29], although the positions of the hydrogen atoms were not reported. Recently, the structure was restudied and the hydrogens were also found [30]. The crystal structure of the so-called D-(+)amphetamine dihydrogen phosphate (or S-amphetamine dihydrdogenphosphate, $\left(\mathrm{C}_{9} \mathrm{H}_{13} \mathrm{~N}\right) \mathrm{H}_{2} \mathrm{PO}_{4}$, has also been reported [31]. The absolute configuration was $\mathrm{S}$ so the conformational geometry in the dihydrogen phosphate would be called S-ZN, in our notation. Probably this is the most stable form for protonated AMP. In the following we use the designation $\mathrm{AMPH}^{+}$for the amphetammonium ion.

By use of DFT calculations at the MP2/6-31G(d,p) level - as well as by rotational spectroscopy - it has been found [28] that the S-AMP molecule in the gas phase is most stable in the S-ZC conformation (with the amino group rotated such as shown in the second diagram in Fig. 1 (a). These calculations however did not involve modelling of vibrational spectra, but are now presented in this paper.

\subsection{Samples}

\section{Experimental}

Amphetamine sulfate with CAS No. [60-13-9] was obtained from Sigma Aldrich. For amphetamine sulfate, $\mathrm{C}_{18} \mathrm{H}_{26} \mathrm{~N}_{2} \cdot \mathrm{H}_{2} \mathrm{O}_{4} \mathrm{~S}$, we prefer to use full names di-amphetammonium sulfate and di-D-amphetammonium sulfate. For the latter, $0.0053 \mathrm{~g}$ was dissolved in $180 \mu \mathrm{L}$ of ultra-pure $\mathrm{H}_{2} \mathrm{O}$ giving a concentration of $29 \mathrm{mg} / \mathrm{mL} \approx 0.08 \mathrm{M}(\mathrm{AMPH})_{2} \mathrm{SO}_{4}$ (equivalent to a 0.16 $\mathrm{M} \mathrm{AMPH}^{+}$solution). For DL-amphetammonium sulfate, $0.0059 \mathrm{~g}$ was dissolved in $200 \mu \mathrm{L}$ of

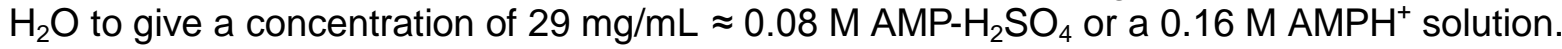

Two street drug powder samples ( $\mathrm{A}$ and $\mathrm{B})$ were obtained from the London Police. For drug $\mathrm{A}$, $0.0120 \mathrm{~g}$ was dissolved in $200 \mu \mathrm{L}$ of $\mathrm{H}_{2} \mathrm{O}$ giving a concentration of $60 \mathrm{mg} / \mathrm{mL}$. For drug powder $\mathrm{B}, 0.0128 \mathrm{~g}$ was dissolved in $200 \mu \mathrm{L}$ of $\mathrm{H}_{2} \mathrm{O}$ giving a concentration of $64 \mathrm{mg} / \mathrm{mL}$. These two sample solutions were microspun for $5 \mathrm{~min}$ at $1000 \mathrm{rpm}$ in filter vials (Lida Microspin Filter, 0.2 $\mu \mathrm{m}$ PES, PP w/RCV+cap, Cat\# 8508-00). An estimated $10 \%$ of the sample volume was lost by this procedure. The solutions were kept and measured in closed $2 \mathrm{~mL}$ glass vials.

To study the effect of basicity or acidity on AMP samples, $0.1 \mathrm{M}$ solutions of sodium hydroxide and hydrochloric acid were used, respectively, with $1 \mathrm{~mL}$ being added to $30 \mathrm{mg}$ of either di-D- or DL-amphetammonium sulfate. For further studies of the effect of the sodium hydroxide concentration, $15 \mathrm{mg}$ of DL-amphetammonium sulfate was added to $0.5 \mathrm{~mL}$ of $0.05,0.11$ and $0.33 \mathrm{M}$ sodium hydroxide and the resulting solutions were centrifuged prior to analysis.

To study the effect of barium hydroxide concentration on the Raman spectrum of DLamphetamine sulfate, a $0.087 \mathrm{M}$ stock solution was prepared (32 $\mathrm{g} / \mathrm{L}$ in water) and 12.6, 25.6, 51.6 and $101.3 \mathrm{mg}$ of barium hydroxide were added to $1 \mathrm{~mL}$ of the stock solution. $\mathrm{A} \mathrm{Ba}(\mathrm{OH})_{2}$ solution (15.6 mg of barium hydroxide in water) containing no amphetamine sulfate was also prepared. 
For the SERS measurements, we used Ag-colloids, which were produced by the silver nitrate hydroxylamine reduction method [32], resulting in grey-brown colloid solution, which we found necessary to dilute with ultra-pure water (50:50) for better performance. An amount of $600 \mu \mathrm{L}$

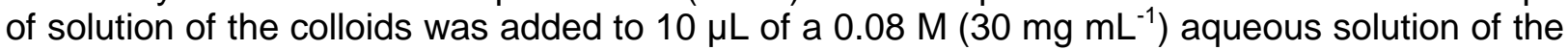
di-D- or DL-amphetammonium sulfate sample, to achieve an $\mathrm{AMPH}^{+}$concentration of $2.6 \mathrm{mM}$.

\subsection{Raman Spectra}

Raman spectra were obtained using a LABRAM Raman Spectrometer (Horiba Jobin-Yvon) and a DILOR-XY $800 \mathrm{~mm}$ focal length spectrometer fitted with a $514.5 \mathrm{~nm}$ argon-ion laser (15-400 $\mathrm{mW})$ and a $632 \mathrm{~nm}$ helium-neon laser $(40 \mathrm{~mW})$ respectively. Both instruments were equipped with microscopes, which were used both for focusing the incident laser and for collecting the Raman scattering. For liquid samples, sample holders with an X4 objective lens were employed for positioning of the glass vials, which contained the sample solutions. The solid samples were placed on microscope slides with the laser beam focused on the sample through X10 objective lenses. Notch filters were used to filter the Rayleigh scattering. The spectrometers were calibrated with reference to the $520 \mathrm{~cm}^{-1}$ band from a silicon wafer and Raman lines of cyclohexane [33]. The laser power on the sample was selected depending on the experiments conducted and determined by the use of a LaserCheck power meter (Coherent). Spectra were obtained by detecting the scattered light with Peltier cooled $(200 \mathrm{~K})$ or LN cooled $(140 \mathrm{~K}) \mathrm{CCD}$ detectors, using different numbers of accumulations and exposure times, depending on the sample and the excition wavelength.

\subsection{Ab Initio Calculations}

To assist assigning the spectra obtained by Raman measurements, and to achieve a better understanding of the origin of the vibrational bands, we have performed ab initio quantum chemical molecular orbital calculations using the Gaussian 03W program package [34]. Estimated geometries of species, assumed to be in hypothetical gaseous free state with minimal symmetry, were used as inputs. Complete geometry optimisations were done and harmonic frequencies and corresponding first order spectra calculated. The HartreeFock/Kohn-Sham density functional theory (DFT) approach was used in order to account for the electron correlation effects in the conjugated molecular system. The hybrid method B3LYP, including a mixture of restricted Hartree-Fock and DFT exchange terms and the Becke threeparameter (B3) gradient-corrected correlation and exchange functional of Lee, Yang and Parr (LYP), was used along with Pople's polarisation split valence Gaussian basis set functions, augmented with $d$ - and p-type polarisation functions and diffuse orbitals on non-hydrogen orbitals $(6-311+G(d, p)$ or $6-311 G(d, p)$ basis sets). The Gaussian 03W software [34] was used as implemented, with the modified GDIIS algorithm and tight optimisation convergence criteria. Optimised results are given as sums of electronic and thermal free energies in atomic units (A.U.), not including the zero point energy corrections. The vibrational frequencies and eigenvectors for each normal mode were calculated without adjusting force constants. The wavenumber scales in such calculations are often calculated as too high, due to the lack of modelling of the surroundings. In the gas phase an empirical scale factor of 0.95 has sometimes been used in order to obtain, by experience, fairly accurate vibrational values. A scaling factor of 1 was however used in the current work.

The optimised structures of different conformations of AMP and $\mathrm{AMPH}^{+}$can be seen in Fig. 1, and the minimised energies of these conformations are given in Table 1.

The calculated spectral bands were assigned to normal modes on the basis of potential energy distribution analysis and typical results for one example, the S-ZN AMPH ${ }^{+}$ion, are presented in Table 2 with a comparison to the Raman measurement of the powder D-(AMPH) ${ }_{2} \mathrm{SO}_{4}$. 
Far-from-resonance Raman spectra were also calculated, and selected ranges of the spectra (in units of $\AA^{4} / A M U$ ) are shown in Fig. 2 and 3. Calculated Raman scattering spectra and IR emission spectra over the entire range $4000-0 \mathrm{~cm}^{-1}$ are given in the Appendix as supplementary figures S1 and S2.

The calculated Raman spectra show differences between the conformers of AMP and AMPH ${ }^{+}$, due to the difference in internal rotation within each species, corresponding to whether the structure is S-ZN, S-ZC or S-ZH (Fig. 1). Considering the results for the AMP conformers, it is clear in the lower half sections of Fig. 2 and Fig. 3 that the spectra of S-ZN AMP and S-ZC AMP are generally alike whereas the S-ZH AMP differs from the others. This difference can be seen in the high-frequency-region (3600-2800 cm-1 ) in Fig. 2 (lower half) as well as in the lowfrequency-region $\left(1750-0 \mathrm{~cm}^{-1}\right)$, except perhaps around $1100 \mathrm{~cm}^{-1}$. The calculations show that the rotational freedom around the C7-C8 bond of the AMP molecule leads to quite remarkable changes in the spectra. Therefore, the spectra should represent good indicators to sense the conformational state of the AMP molecule. This feature has not been taken into consideration in any of the earlier reported observations.

The protonated form, i.e. $\mathrm{AMPH}^{+}$, appears to behave differently than AMP, as seen in the upper parts of Fig. 2 and Fig. 3. Here, we find that especially the S-ZN AMPH ${ }^{+}$differs from the other species, both in the high- and low-frequency regions, and hence indicates another theoretical consideration, which should be taken into account when amphetamine compounds are to be investigated by Raman spectroscopy.

\section{Results and Discussion}

\subsection{Solids and Aqueous Solutions}

The experimental Raman spectra of solid DL- and di-D-amphetammonium sulfate are shown in Fig. 4 (in red and black, respectively). Whereas the two spectra are more or less alike in the low-frequency-range (2000-200 cm $\left.\mathrm{cm}^{-1}\right)$, it can be seen that their Raman spectra differ substantially in the high-frequency range, especially at around $3000 \mathrm{~cm}^{-1}$. It is worth mentioning that specific features in a Raman spectrum of the same crystal of a crystalline material can also be different, when the crystal is turned with respect to the incident beam [35], [36]. This is due to orientation effects of the crystal faces with respect to the direction and polarisation of the laser beam. Also, it would be expected that the vibrational mode couplings in the racemic crystal are different from those in the chiral case because of expected structure differences among the phases (only one of the crystal structures is known).

As mentioned, the X-ray crystal structure of the solid sulfate of the D-form has been determined [29] [30]. Here the $\mathrm{AMPH}^{+}$ion adopts a geometry, that is quite similar to our calculated S-ZN conformation. For comparison, therefore, the calculated spectrum of the $\mathrm{AMPH}^{+}$in the S-ZN conformation is incorporated into Fig. 4 (shown in blue). To facilitate comparisons the observed spectral band positions are given in Table 2, in which also tentative band assignments are listed. The assignments are derived from the calculated normal modes, but for a number of cases it is not trivial to decide to which mode/modes an observed band belongs, partly since other phenomena, such as Fermi resonances, are not included in the modelling.

As one can see in the measured spectra in Fig. 4, three bands appear at positions near $\sim 1000$ $\mathrm{cm}^{-1}$, whereas only two strong Raman bands are found in the same region in the calculated 
spectrum for $\mathrm{AMPH}^{+}$, independent of the conformation (see also Fig. 3). On the other hand the measured spectra in Fig. 4 look much like other spectra, reported earlier for amphetamine sulfate, as discussed in section 1.1. The reason for this seems to be that the band at $\sim 975 \mathrm{~cm}^{-1}$ in the solid samples is due to the $v_{1} \mathrm{SO}_{4}{ }^{2-}$ symmetric stretching mode. This is in accordance with the fact that the $v_{1} \mathrm{SO}_{4}{ }^{2-}$ sym. str. band appears strongly at $\sim 983 \mathrm{~cm}^{-1}$ in many solid sulfate salts [37]. Hence, it seems that spectra of the amphetammonium ion on its own should not have a distinct band at $\sim 975 \mathrm{~cm}^{-1}$. This is in disaccord with the spectra reported in several references, e.g. [13] and [14], where spectra were given as due to "amphetamine" but probably originated from the dihydrogenated salt, $(\mathrm{AMPH})_{2} \mathrm{SO}_{4}$. We believe that the authors did not differentiate between the base AMP and protonated salts of the base, which could have consequences reflected in the spectra, and it is, at the end, scientifically incorrect. For illustrating this, we demonstrate later, in section 3.2, how the effect on AMP of being acidic or basic can be seen in the Raman spectra.

In Fig. 5, the Raman spectrum of a solid crystalline di-D-amphetammonium sulfate sample is depicted, and compared to the Raman spectra of the DL- and di-D-amphetammonium sulfate salts dissolved in water. The samples in water showed nice Raman spectra, though with some fluorescence background (probably due to impurities), that however dropped to acceptable levels within an hour of measuring (bleaching by the laser excitation). As expected a fine correspondence can be seen, because the D- and L-species should give identical Raman spectra in solution (Raman spectroscopy is insensitive to chirality unless circularly polarised light is employed, which is not the case here). The bands for samples in solution are broader than those for the solid state, and naturally the bending mode of water is seen as a broad band around $1600 \mathrm{~cm}^{-1}$. Some background fluorescence was seen for the DL-sample, probably due impurities. Again here, near $1000 \mathrm{~cm}^{-1}$, three strong bands are visible. The band at around 981 $\mathrm{cm}^{-1}$ (marked with an asterisk) is the $v_{1} \mathrm{SO}_{4}{ }^{2-}$ sym. str., which in aqueous solutions often is seen as a polarised distinct band at $\sim 98 \mathrm{~cm}^{-1}$ [38], [39]. The bands at 1005 and $1033 \mathrm{~cm}^{-1}$ must be due to $\mathrm{AMPH}^{+}$or due to a possible mixture of $\mathrm{AMPH}^{+}$and free AMP. Usually, bands due to the breathing vibration of an aromatic ring, e.g. in phenylalanine, appear in this range. This is also obvious from the calculated spectrum, seen in Fig. 5 (shown in red). It is not known what conformation the $\mathrm{AMPH}^{+}$ion is taking in solution, so for the reason of comparison, it is the calculated sum of the three $\mathrm{AMPH}^{+}$conformations that is included in Fig. 5 (in red), and a quite convincing correspondence is apparent. Some of the spectral data are summarised in Table 3.

\subsection{Acidic and Basic Solutions}

The behaviour in acidic and basic aqueous solutions was studied as described in the following. When enough hydrochloric acid was added to the di-amphetammonium sulfate solutions, sole occurrence of definitely protonated $\mathrm{AMPH}^{+}$ions can be expected in solution, which also must contain larger amounts of $\mathrm{HSO}_{4}^{-}$. This behaviour is clearly supported, as shown in Fig. 6 (red curves), where bands at 1049-1052 $\mathrm{cm}^{-1}$ are seen for DL- and di-D-AMPH ${ }^{+}$. This band is interpreted as due to the $v_{1} \mathrm{HSO}_{4}{ }^{-}$sym. str. and has often been seen polarised around 1040$1050 \mathrm{~cm}^{-1}$ in aqueous solutions [40] and molten salts [41], [42], [43].

On the other hand, when enough sodium hydroxide was added to the di-amphetammonium sulfate solutions, one would expect formation of free amphetamine in solutions that also contained sodium sulfate. This behaviour is indeed supported, as seen in Fig. 6 (blue curves). The $v_{1} \mathrm{HSO}_{4}^{-}$sym. str. band at around $1050 \mathrm{~cm}^{-1}$ disappears almost completely and the $v_{1}$ $\mathrm{SO}_{4}{ }^{2-}$ sym. str. band, around $980 \mathrm{~cm}^{-1}$, stays intense in spite of the addition of $\mathrm{NaOH}$ to either DL- or di-D-amphetammonium sulfate, while the bands at 1033 and $1005 \mathrm{~cm}^{-1}$, as expected, remain strong. 
In another series of experiments, we added $\mathrm{NaOH}$ to $\mathrm{DL}-\mathrm{AMPH}^{+}$sulfate and recorded the Raman spectra and determined the basicity with $\mathrm{pH}$ papers. The results are shown in Fig. 7, where no evidence of a band around $1050 \mathrm{~cm}^{-1}$ was seen, meaning that here, no band due to $\mathrm{HSO}_{4}{ }^{-}$could be present because of the conversion to sulfate.

\subsection{Effect of Addition of $\mathrm{Ba}(\mathrm{OH})_{2}$}

To verify the assignment of the sulfate bands, a $30 \mathrm{mg} / \mathrm{mL}$ solution of DL-amphetammonium sulfate was prepared by dissolving $161.1 \mathrm{mg}$ in $5 \mathrm{~mL}$ of water. This solution was added to tubes containing various amounts of $\mathrm{Ba}(\mathrm{OH})_{2}$, as described in Table 4.

The mixtures were homogenised by whirlmixing, ultrasoniced and finally centrifuged for 10 minutes at $10000 \mathrm{rpm}$ to precipitate the insoluble $\mathrm{BaSO}_{4}$. The supernatant solution was transferred to glass vials and Raman spectra were recorded. The $\mathrm{pH}$ was determined with $\mathrm{pH}$ papers, and the Raman spectra are plotted in Fig. 8. Interestingly, the samples, which contained enough $\mathrm{Ba}(\mathrm{OH})_{2}$ to precipitate all the sulfate as $\mathrm{BaSO}_{4}$, provided only two main peaks; at $\sim 1005$ and $\sim 1033 \mathrm{~cm}^{-1}$, and the peak at $983 \mathrm{~cm}^{-1}$ disappeared along with the precipitation of the sulfate, going from $A$ to $E$ in Fig. 8. It is also noticeable that neither AMP nor $\mathrm{AMPH}^{+}$has a band at about $1050 \mathrm{~cm}^{-1}$, so the weak bands at $-1050 \mathrm{~cm}^{-1}$ in Fig. 6 must be due to traces of $\mathrm{HSO}_{4}^{-}$. The spectra naturally became weaker with increasing amounts of $\mathrm{Ba}(\mathrm{OH})_{2}$ because of dilution.

\subsection{AMP Oil Droplets}

When enough $\mathrm{NaOH}$ was added to the $\mathrm{DL}-\mathrm{AMPH}^{+}$sulfate solution it went cloudy, and when centrifuged, an oily droplet was seen floating on the aqueous phase. Hence, two tubes, each containing $\sim 30 \mathrm{mg} \mathrm{DL-AMPH}{ }^{+}$sulfate and $\sim 0.5 \mathrm{~mL} 0.33 \mathrm{M} \mathrm{NaOH}$, were whirlmixed and centrifuged to separate the aqueous phases from the oily droplets. The aqueous phases gave spectra like the basic ones, shown in Fig. 7. The oily droplets were placed on glass slides using pipettes and measured. The spectra of the oil droplets, shown in Fig. 9, proved that the oil consisted of AMP. It is interesting to note how good the correspondence is between the measured AMP spectrum and the calculated spectrum, also shown in Fig. 9. It is also to be noted that the AMP spectrum fits very well with pre-resonance Raman spectrum, reported by Saegmüller et al. [19], who also have found only two bands around $1000 \mathrm{~cm}^{-1}$, in contrast to the many spectra claimed to be AMP in the literature, but actually must have been the sulfate (see discussion in section 1.1). Data for our spectral bands of AMP are included in Table 3.

\subsection{Street Samples}

The two street drug powder samples ( $A$ and $B$ ) that we had access to were examined in aqueous solutions. Initially the solutions gave large fluorescence, drowning the Raman signals, and even though the fluorescent backgrounds decreased with time during illumination, no useful spectra could be obtained. After thorough mixing it looked as if small insoluble particles were present, and thus we tried filtering because the drug should be soluble. Indeed, the fluorescence was greatly reduced, but the background remained significantly higher than seen for the pure amphetamine samples. The Raman spectra of the two street samples compared to the di-D-amphetamonium sulfate in water are depicted in Fig. 10. Here, it can clearly be seen that the street drug samples were likely to contain di-amphetammonium sulfate, in spite of blurring from some unidentified bands (UIS), which are probably originating from soluble dilution ingredients. From the intensity of the $\mathrm{AMPH}^{+}$bands relative to the water bending band (around $1600 \mathrm{~cm}^{-1}$ ), the concentrations of $\mathrm{AMPH}^{+}$seemed to be about the same as in the reference, meaning that both solid street drugs probably were $(\mathrm{AMPH})_{2} \mathrm{SO}_{4}$ diluted at about $50 \%$ by weight. 
Hargreaves et al. [24] assigned a very strong band at $976 \mathrm{~cm}^{-1}$ to be $v \mathrm{SO}_{4}{ }^{2-}$ asym in $(\mathrm{AMPH})_{2} \mathrm{SO}_{4}$. This is probably a mistake or printing error, as it is the symmetrical stretching. More importantly, they used this band as a marker for amphetamine (like the company Horiba Jobin-Yvon in their note \# 1 on forensic applications of Raman spectroscopy). This is not wise. If one would use marker bands to detect presence of amphetamine compounds, one should only use perhaps the two bands at $\sim 1005$ and $1033 \mathrm{~cm}^{-1}$, not the $\sim 980 \mathrm{~cm}^{-1}$ band of sulfate.

\subsection{SERS Measurements}

Experiments were also done to obtain SERS spectra of the samples. Solutions of DL-AMPH ${ }^{+}$

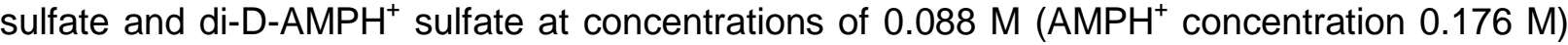
were diluted to obtain $2.6 \mathrm{mM} \mathrm{AMPH}^{+}$solutions containing also Ag-colloids, and the SERS spectra, compared to the Raman spectrum and the calculated Raman spectrum, are shown in Fig. 11.

When comparing SERS spectra to the Raman spectrum, the enhancements of most of the bands are obvious. However, some of the bands are seen more enhanced than others. Most interestingly, it seems that the sulfate $v_{1}$ stretching band, at $981 \mathrm{~cm}^{-1}$, disappears in SERS spectra. Although the SERS spectra were obtained for concentrations, which were at least two orders of magnitude less than those used for the Raman spectrum, we should still have the same relative concentration of $2: 1$ for $\mathrm{AMPH}^{+} / \mathrm{SO}_{4}{ }^{2-}$. This is not borne out in the spectra, and must mean that $\mathrm{AMPH}^{+}$(or AMP) species are enhanced, whereas the sulfate is not. The reason for this is probably the negative charge of the sulfate, or due to geometric features of the adsorption, in which the sulfate may lie far away from the nano-particles.

As first reported by Faulds et al. [15], we also observed only two peaks near $1000 \mathrm{~cm}^{-1}$. According to the previous discussion and what has been shown in Figs. 6-9, it seems that one detects either AMP molecules or $\mathrm{AMPH}^{+}$ions, which are adsorbed on the surfaces of the colloid particles, even when sulfate ions are present in the solutions. SERS results thus cannot exclude the presence of sulfate in spite of the absence of the sulfate band at $981 \mathrm{~cm}^{-1}$. It is also worth noticing that their work [15] was done by using $785 \mathrm{~nm}$ excitation, whereas here we have achieved similar or better signals with $514.5 \mathrm{~nm}$ excitation. This allows for a detection of more weak bands, which also can be seen when our SERS spectra are compared to those of ref. [15].

\section{Conclusions}

$A b$ initio model calculations and Raman and SERS spectra of amphetamine and amphetamine$\mathrm{H}^{+}$have been studied and assigned. Complete geometry minimisations of the conformational energy of the S-plus-amphetamine molecule and the S-plus-amphetamine- $\mathrm{H}^{+}$ion followed by calculation of Raman spectra have been done. For the first time, the differences between the spectra of amphetamine and amphetamine- $\mathrm{H}^{+}$have been obtained and between different conformers yielding information about the characteristic features of these species. The results achieved here have shown that vibrational bands from salt anions with internal bonds (sulfates, hydrogen phosphates, etc.) need to be taken into account when employing spectra for identification purposes. Two street samples were also measured and it was found that for detection of illicit samples differentiation should be made between amphetamine and the protonated version in salts, as their spectra are different. Experimental characterisation has been provided of how acidity and basicity affect the spectra of amphetamine. 


\section{Acknowledgements}

Professor Irene Shim of DTU Chemistry is thanked for advice during the calculations. The Danish Centre for Scientific Computing is acknowledged for providing the computational resources. Director Ib Henriksen's Foundation is thanked for maintenance of the Raman instrumentation. The Danish Agency for Science, Technology and Innovation helped contribute funding (\#09-065038/FTP) for this project.

\section{References}

[1] Rasmussen, L. B.; Olsen, K. H. \& Johansen, S. S. "Chiral separation and quantification of R/S- amphetamine, R/S-methamphetamine, R/S-MDA, R/S-MDMA, and R/S-MDEA in whole blood by GC-EI-MS", J. Chromatogr. B: Anal. Technol. Biomed. \& Life Sci. 2006; 842(2): 136141.

[2] Meyer, E.; Van Bocxlaer, J. F.; Dirinck, I. M.; Lambert, W. E.; Thienpont, L.; De Leenheer, A. P., "Tissue distribution of amphetamine isomers in a fatal overdose". Belg. J. of Analytical Toxicology 1997; 21(3): 236-239.

[3] Dirinck, I., Meyer, E., Van Bocxlaer, J., Lambert W., and De Leenheer, A., "Application of gas chromatography-Fourier transform infrared spectrometry to the analysis of amphetamine analogues", J. Chromatogr. 1998; 819(1-2): 155-159.

[4] Maurer, Hans H.; Kraemer, Thomas; Springer, Dietmar; Staack, Roland F. "Chemistry, pharmacology, toxicology, and hepatic metabolism of designer drugs of the amphetamine (ecstasy), piperazine, and pyrrolidinophenone types. A synopsis". Therapeutic Drug Monitoring 2004; 26(2): 127-131.

[5] Kraemer, Thomas; Maurer, Hans H.; "Determination of amphetamine, methamphetamine and amphetamine-derived designer drugs or medicaments in blood and urine", J. Chromatogr. 1998; B713: 163-187.

[6] Peters, F.T., Kraemer, T., Maurer, H.H., "Drug testing in blood: Validated negative-ion chemical ionization gas chromatographic-mass spectrometric assay for determination of amphetamine and methamphetamine enantiomers and its application to toxicology cases". Clinical Chemistry, 2002; 48(9): 1472-1485.

[7] Hegedüs, H.; Gergely, A.; Veress, T.; Zsila, F., "Determination of the enantiomeric purity of amphetamine after derivatization with Sanger's reagent (2,4-dinitrofluorobenzene) by simultaneous dual circular dichroism and ultraviolet spectroscopy". Fresenius' J. Anal. Chem. 1999; 364(8): 749-752.

[8] De Gelder, J.; De Gussem, K.; Vandenabeele, P.; Moens, L., Reference database of Raman spectra of biological molecules, J. Raman Spectrosc. 2007; 38: 1133-1147.

[9] Kneipp, K.; Kneipp, H.; Abdali, S.; Berg, R. W.; Bohr, H. "Single Molecule Raman Detection of Enkephalin on Silver Colloidal Particles" Spectroscopy 2004; 18(3): 433-440. 
[10] Bass, V. C., "The identification of sympathomimetic amines by Raman spectroscopy", Forensic Science 1978; 11(1): 57-65.

[11] Hodges, C. M.; Akhavan, J. The use of Fourier transform Raman spectroscopy in the forensic identification of illicit drugs and explosives. Spectrochim. Acta, Part A: Molecular and Biomolecular Spectroscopy 1990; 46A(2): 303-307.

[12] Tsuchihashi, H.; Katagi, M.; Nishikawa, M.; Tatsuno, M.; Nishioka, H.; Nara, A.; Nishio, E.; Petty, C., "Determination of methamphetamine and its related compounds using Fourier transform Raman spectroscopy". Appl. Spectrosc. 1997; 51(12): 1796-1799.

[13] Bell, S. E. J.; Burns, D. T.; Dennis, A. C.; Speers, J. S., "Rapid analysis of ecstasy and related phenethylamines in seized tablets by Raman spectroscopy". Analyst 2000; 125(3): 541-544.

[14] Carter, J. C.; Brewer, William E.; Angel, S. Michael. "Raman spectroscopy for the in situ identification of cocaine and selected adulterants" Applied Spectrosc. 2000; 54(12): 1876-1881.

[15] Faulds, K., Smith, W.E., Graham D., Lacey, R.J., "Assessment of silver and gold substrates for the detection of amphetamine sulfate by surface enhanced Raman scattering (SERS)" Analyst 2002; 127: 282-286.

[16] Day, J. S.; Edwards, H. G. M.; Dobrowski, S. A.; Voice, A. M., "The detection of drugs of abuse in fingerprints using Raman spectroscopy I: latent fingerprints" Spectrochim. Acta, 2004; 60A(3): 563-568.

[17] Day, J. S.; Edwards, H. G. M.; Dobrowski, S. A.; Voice, A. M, "The detection of drugs of abuse in fingerprints using Raman spectroscopy II: cyanoacrylate-fumed fingerprints" Spectrochim. Acta, 2004; 60A(8-9): 1725-1730.

[18] Saegmuller, B.; Schwarze, B.; Brehm, G.; Trachta, G.; Schneider, S., "Identification of illicit drugs by a combination of liquid chromatography and surface-enhanced Raman scattering spectroscopy" J. Mol. Struct. 2003; 661-662: 279-290.

[19] Saegmüller, B.; Schwarze, B., Brehm, G.; Schneider, S., "Application of SERS spectroscopy to the identification of (3,4-methylenedioxy)amphetamine in forensic samples utilizing matrix stabilized silver halides" Analyst 2001; 126(11): 2066-2071.

[20] Ruperez, A.; Montes, R.; Laserna, J. J., "Identification of stimulant drugs by surfaceenhanced Raman spectrometry on colloidal silver". Vibrational Spectroscopy 1991; 2(2-3): 145-54.

[21] Sulk, Roberta A.; Corcoran, Robert C.; Carron, Keith T. "Surface-enhanced Raman scattering detection of amphetamine and methamphetamine by modification with 2mercaptonicotinic acid", Appl. Spectrosc. 1999; 53(8): 954-959.

[22] Milhazes, Nuno; Borges, Fernanda; Calheiros, Rita; Marques, M. Paula M. "Identification of synthetic precursors of amphetamine-like drugs using Raman spectroscopy and ab initio calculations: $\beta$-Methyl- $\beta$-nitrostyrene derivatives". Analyst 2004; 129(11): 1106-1117.

[23] Rasmussen, K. E.; Knutsen, P., "Techniques for the detection and identification of amphetamines and amphetamine-like substances". Bull. on Narcotics 1985; 37(1): 95-112. 
[24] M. D. Hargreaves, K. Page, T. Munshi, R. Tomsett, G. Lynch and H. G. M. Edwards, "Analysis of seized drugs using portable Raman spectroscopy in an airport environment - a proof of principle study", J. Raman Spectrosc. 2008; 39: 873-880.

[25] Hargreaves, M. D.; Burnett, A. D.; Munshi, T.; Cunningham, J. E.; Linfield, E. H.; Davies, A. G.; Edwards, H. G. M. "Comparison of near infrared laser excitation wavelengths and its influence on the interrogation of seized drugs-of-abuse by Raman spectroscopy", J. Raman Spectros. 2009; 40: 1974-1983.

[26] Katainen E., Elomaa M., Laakkonen U.-M., Sippola E., Niemelä P., Suhonen J.and Järvinen K., "Quantification of Amphetamine Content in Seized street Samples by Raman Spectroscopy, J. Forensic Sci. 2007; 52(1): 88-92.

[27] West, M. J.; Went, M. J., "The spectroscopic detection of drugs of abuse on textile fibers after recovery with adhesive lifters", Forensic Science International 2009; 189(1-3): 100-103.

[28] Godfrey P.D., McGlone S.J. and Brown R.D., "The shapes of neurotransmitters by millimetrewave spectroscopy: amphetamine", J. Mol. Struct. 2001; 599(1-3): 139-152.

[29] Bergin R. and Carlström D., "Crystal and molecular structure of amphetamine sulfate", Acta Cryst. 1971; B27: 2146-2152.

[30] Pogorzelec-Glaser K., Kaszynska J., Rachocki A., Tritt-Goc J., Pislewski N., Pietraszko A., "The crystal structure and evidence of the phase transition in d-amphetamine sulfate, as studied by X-ray crystallography, DSC and NMR spectroscopy", New J. Chem., 2009; 18941900.

[31] Herbert, H., "X-ray structure of (+)-AmpH ${ }^{+} \mathrm{H}_{2} \mathrm{PO}_{4}{ }^{-"}$, Acta Crystallogr. 1978; B34: 611-615.

[32] Leopold, N. and Lendl B, A New Method for Fast Preparation of Highly Surface-Enhanced Raman Scattering (SERS) Active Silver Colloids at Room Temperature by Reduction of Silver Nitrate with Hydroxylamine Hydrochloride, J.Phys, Chem. B 2003; 107: 5723-5727.

[33] Berg R. W. and Nørbygaard T.: "Wavenumber Calibration of CCD Detector Raman Spectrometers Controlled by a Sinus Arm Drive", Applied Spectroscopy Reviews, 2006; 41(2): 165-183.

[34] Frisch, M. J. T., G. W.; Schlegel, H. B.; Scuseria, G. E.; Robb, M. A.; Cheeseman, J. R.; J. A. Montgomery, J.; Vreven, T.; Kudin, K. N.; Burant, J. C.; Millam, J. M.; Iyengar, S. S.; Tomasi, J.; Barone, V.; Mennucci, B.; Cossi, M.; Scalmani, G.; Rega, N.; Petersson, G. A.; Nakatsuji, H.; Hada, M.; Ehara, M.; Toyota, K.; Fukuda, R.; Hasegawa, J.; Ishida, M.; Nakajima, T.; Honda, Y.; Kitao, O.; Nakai, H.; Klene, M.; Li, X.; Knox, J. E.; Hratchian, H. P.; Cross, J. B.; Adamo, C.; Jaramillo, J.; Gomperts, R.; Stratmann, R. E.; Yazyev, O.; Austin, A. J.; Cammi, R.; Pomelli, C.; Ochterski, J. W.; Ayala, P. Y.; Morokuma, K.; Voth, G. A.; Salvador, P.; Dannenberg, J. J.; Zakrzewski, V. G.; Dapprich, S.; Daniels, A. D.; Strain, M. C.; Farkas, O.; Malick, D. K.; Rabuck, A. D.; Raghavachari, K.; Foresman, J. B.; Ortiz, J. V.; Cui, Q.; Baboul, A. G.; Clifford, S.; Cioslowski, J.; Stefanov, B. B.; Liu, G.; Liashenko, A.; Piskorz, P.; Komaromi, I.; Martin, R. L.; Fox, D. J.; Keith, T.; Al-Laham, M. A.; Peng, C. Y.; Nanayakkara, A.; Challacombe, M.; Gill, P. M. W.; Johnson, B.; Chen, W.; Wong, M. W.; Gonzalez, C.; Pople, J. A. Gaussian 03, Revision B.04; Gaussian, Inc.: Pittsburgh PA, 2003.

[35] Bremard, C, Laureyns, J. and Turrell G. "Polarization measurements in Raman microspectroscopy", J. Chimie Physique. 1989; 86(6): 1245-1251. 
[36] Bremard, C, Dhamelincourt P., Laureyns, J. and Turrell G. "The effect of Objectivers on Polarization Measurements in Micro-Raman Spectrometry", Appl. Spectrosc. 1985; 39(6): 1036-1039

[37] Berg R. W. and Thorup N., "The Reaction between $\mathrm{ZnO}$ and Molten $\mathrm{Na}_{2} \mathrm{~S}_{2} \mathrm{O}_{7}$ or $\mathrm{K}_{2} \mathrm{~S}_{2} \mathrm{O}_{7}$ forming $\mathrm{Na}_{2} \mathrm{Zn}\left(\mathrm{SO}_{4}\right)_{2}$ or $\mathrm{K}_{2} \mathrm{Zn}\left(\mathrm{SO}_{4}\right)_{2}$, studied by Raman Spectroscopy and X-ray Diffraction", Inorg. Chem. 2005; 44(10): 3485-3493.

[38] Irish D. E. and Ozeki T.: "Raman spectroscopy of inorganic species in solution", Table 4.1, p.71. Chapter 4, p. 59-106, in Analytical Raman Spectroscopy, Edited by J. G. Grasselli and B. J. Bulkin, Chemical Analysis, series vol. 114. J. Wiley \& Sons, Inc., ISBN 0-471-51955-3, 1991.

[39] Nakamoto K., "Infrared and Raman Spectra of Inorganic and Coordination Compounds", $5^{\text {th }}$ Edition part A, p. 199, J. Wiley \& Sons, Inc., ISBN 0-471-16394-5, 1997.

[40] Knopf D. A., Luo B. P., Krieger U. K. and Koop T., "Thermodynamic Dissociation Constant of the bisulphate Ion from Raman studies", J. Phys. Chem. A, 2003; 107: 4322-4332.

[41] Fehrmann R., Hansen N.H. and Bjerrum N.J., "Raman Spectroscopic and Spectrophotometric Study of the System $\mathrm{K}_{2} \mathrm{~S}_{2} \mathrm{O}_{7}-\mathrm{KHSO}_{4}$ in the Temperature range 200-450 ${ }^{\circ} \mathrm{C}$ ", Inorg. Chem. 1983, 22: 4009-4014.

[42] Rasmussen S.B., Hamma H., Lapina O.B., Khabibulin D.F., Eriksen K.M., Berg R. W., Hatem G.and Fehrmann R.: "Thermal, Conductivity, NMR and Raman Spectroscopic Measurements and Phase Diagram of the $\mathrm{Cs}_{2} \mathrm{~S}_{2} \mathrm{O}_{7}-\mathrm{CsHSO}_{4}$ System". J. Phys. Chem. B, 2003; 107: $13823-13830$.

[43] Knudsen C. B., Kalampounias A.G., Fehrmann R. and Boghosian S., Thermal Dissociation of Molten $\mathrm{KHSO}_{4}$ : "Temperature Dependence of Raman Spectra and Thermodynamics", J. Phys. Chem. B, 2008; 112: 11996-12000. 
Table 1. Minimised energies of the optimized structures of Amphetamine AMP and Amphetammonium AMPH ${ }^{+}$species calculated by the Gaussian 03W DFT / B3LYP procedure as explained in the text.

\begin{tabular}{|c|c|c|}
\hline Conformation & AMP & AMPH $^{+}$ \\
\hline Gaussian Model & $6-311+\mathrm{G}(\mathrm{d}, \mathrm{p})$ & $6-311 \mathrm{G}(\mathrm{d}, \mathrm{p})$ \\
\hline S-ZH & $-405.65 \underline{35} 035$ a.u. & $-406.0 \underline{23} 5207$ a.u. \\
\hline S-ZC & $-405.65 \underline{533380}$ a.u. & $-406.0 \underline{25} 8354$ a.u. \\
\hline S-ZN & $-405.65 \underline{466681}$ a.u. & $-406.0 \underline{19} 2322$ a.u. \\
\hline R-ZN & $-405.65 \underline{46681}$ a.u. & \\
\hline
\end{tabular}


Table 2. Calculated vibrational spectra for the S-ZN $[A M P H]^{+}$ion and corresponding assignments, compared to measured Raman spectra for solid $\mathrm{D}-(\mathrm{AMPH})_{2} \mathrm{SO}_{4}$ * $^{*}$

\begin{tabular}{|c|c|c|c|c|c|}
\hline Mode no. & $\begin{array}{c}\text { Wave } \\
\text { number } \\
\left(\mathrm{cm}^{-1}\right)\end{array}$ & $\begin{array}{c}\text { Raman } \\
\text { activity } \\
\left(\AA^{4} / \mathrm{AMU}\right)\end{array}$ & $\begin{array}{c}\text { Depolar- } \\
\text { isation ratio }\end{array}$ & $\begin{array}{c}\text { Description of } \\
\text { normal mode (Assigment) }\end{array}$ & $\begin{array}{c}\text { Observed } \\
\text { for solid } \\
\text { di-D- } \\
\text { (AMPH) } \text { SO }_{4} \\
\text { (Fig. 4) }\end{array}$ \\
\hline 1 & 46.2 & 4.92 & 0.75 & C1-C7 rot & \\
\hline 2 & 70.0 & 1.14 & 0.75 & C1-C7 rot & \\
\hline 3 & 97.3 & 3.67 & 0.72 & C1-C7-C8 wag & \\
\hline 4 & 215.2 & 0.25 & 0.65 & C8-N twist & \\
\hline 5 & 241.2 & 1.70 & 0.59 & C8-C9 twist & \\
\hline 6 & 245.4 & 1.67 & 0.72 & C8-C9 twist & \\
\hline 7 & 299.0 & 2.35 & 0.29 & C7-C8-N bend & $255 \mathrm{~m}$ \\
\hline 8 & 344.6 & 0.09 & 0.41 & C2-C1-C7 ipl bend & \\
\hline 9 & 380.4 & 0.57 & 0.39 & $\mathrm{CH}_{3}$ rock & $342 \mathrm{w}$ \\
\hline 10 & 414.4 & 0.12 & 0.42 & ring twist & \\
\hline 11 & 419.6 & 1.67 & 0.08 & N-C8-C9 bend & \\
\hline \multirow[t]{2}{*}{12} & 502.9 & 1.38 & 0.49 & skeleton \& ring def & $435 \mathrm{w}$ \\
\hline & & & & sulfate $v_{4}$ bend & \\
\hline 13 & 601.5 & 1.22 & 0.48 & $\mathrm{~N}-\mathrm{C} 8-\mathrm{C} 7 \mathrm{\&}$ ring bend & $466 \mathrm{w}$ \\
\hline 14 & 635.2 & 4.67 & 0.75 & ring ipl def & \\
\hline \multirow[t]{2}{*}{15} & 715.6 & 0.27 & 0.48 & ring oopl def & \\
\hline & & & & sulfate $v_{2}$ bend & \\
\hline 16 & 746.2 & 10.16 & 0.18 & ring oopl def \& N-C8 str & \\
\hline 17 & 780.9 & 3.08 & 0.75 & ring oopl def \& N-C8 str & \\
\hline 18 & 826.0 & 12.21 & 0.03 & C1-C7 str \& NH bend & $\sim 502 \mathrm{~W}$ \\
\hline 19 & 855.6 & 0.59 & 0.75 & ring $\mathrm{CH}$ oopl def & \\
\hline 20 & 871.7 & 6.10 & 0.69 & Chain C-C \& C-N str & $604 \mathrm{w}$ \\
\hline 21 & 903.2 & 1.79 & 0.75 & $\mathrm{CH} \& \mathrm{NH}$ def C7-C8 str & \\
\hline 22 & 934.9 & 0.25 & 0.64 & chain $\mathrm{CH}$ ring $\mathrm{CH}$ oopl def & $623 \mathrm{~m}$ \\
\hline 23 & 940.7 & 1.12 & 0.71 & $\mathrm{NH}_{3}$ rock \& $\mathrm{CH}_{3}$ rock & \\
\hline 24 & 959.3 & 5.24 & 0.75 & $\mathrm{NH}_{3} \& \mathrm{CH}_{3}$ rock \& C8-C9 str & $740 \mathrm{w}$ \\
\hline 25 & 989.1 & 0.04 & 0.48 & ring $\mathrm{CH}$ oopl def & $752 \mathrm{w}$ \\
\hline 26 & 1017.4 & 27.18 & 0.08 & ring skeleton ipl str & \\
\hline 27 & 1023.5 & 0.27 & 0.10 & ring $\mathrm{CH}$ oopl def & $826 \mathrm{~m}$ \\
\hline 28 & 1050.0 & 12.51 & 0.10 & ring CC str \& CH ipl def & $838 \mathrm{~m}$ \\
\hline 29 & 1070.9 & 2.09 & 0.44 & skeleton \& $\mathrm{CH}$ def & \\
\hline 30 & 1092.1 & 0.40 & 0.44 & ring $\mathrm{CC}$ str \& $\mathrm{CH} \& \mathrm{NH}$ def & $897 \mathrm{vw}$ \\
\hline 31 & 1131.2 & 1.35 & 0.73 & ring $\mathrm{CC}$ str \& $\mathrm{CH} \& \mathrm{NH}$ def & \\
\hline 32 & 1190.1 & 2.91 & 0.74 & ring $\mathrm{CH}$ ipl def & $914 \mathrm{vw}$ \\
\hline 33 & 1198.9 & 2.28 & 0.71 & chain str \& CH \& NH def & $942 \mathrm{w}$ \\
\hline 34 & 1206.8 & 4.51 & 0.50 & ring $\mathrm{CH}$ ipl def & \\
\hline 35 & 1218.2 & 16.69 & 0.16 & C1-C7 str \& ring CH ipl def & \\
\hline \multirow[t]{2}{*}{36} & 1262.0 & 3.51 & 0.64 & angle def \& ring $\mathrm{CH}$ ipl def & \\
\hline & & & & sulfate $v_{1}$ sym str & $977 \mathrm{~s}$ \\
\hline 37 & 1335.6 & 5.33 & 0.46 & ring \& chain CC str \& $\mathrm{CH}$ angle def & 1002 vs \\
\hline 38 & 1345.3 & 4.59 & 034 & ring \& chain CC str \& $\mathrm{CH}$ angle def & $1033 \mathrm{~m}$ \\
\hline 39 & 1359.7 & 1.45 & 0.73 & chain CC str \& ring $\mathrm{CH}$ angle def & $1066 \mathrm{vw}$ \\
\hline 40 & 1384.5 & 5.02 & 0.64 & C7-C8 str \& CH def & $1103 \mathrm{vw}$ \\
\hline 41 & 1394.1 & 1.98 & 0.62 & $\mathrm{CH}_{3}$ umbrella \& $\mathrm{CH}$ def & $1158 \mathrm{w}$ \\
\hline 42 & 1425.7 & 2.03 & 0.51 & $\mathrm{CH}_{3}$ umbrella \& $\mathrm{CH}$ bend & $1181 \mathrm{w}$ \\
\hline 43 & 1477.8 & 12.81 & 0.71 & $\mathrm{CH}_{2} \& \mathrm{CH}_{3}$ def & $1210 \mathrm{~m}$ \\
\hline 44 & 1487.5 & 1.61 & 0.75 & ring $\mathrm{CC}$ str \& $\mathrm{CH} \& \mathrm{NH}$ bend & $1246 \mathrm{vw}$ \\
\hline \multirow[t]{3}{*}{45} & 1491.7 & 1.51 & 0.75 & $\mathrm{NH}_{3}$ umbrella \& $\mathrm{CH}$ bend & $1258 \mathrm{vw}$ \\
\hline & & & & & $1301 \mathrm{vw}$ \\
\hline & & & & & $1334 \mathrm{w}$ \\
\hline 46 & 1499.6 & 5.47 & 0.73 & $\mathrm{CH}_{3}$ def & $1367 \mathrm{w}$ \\
\hline 47 & 1501.3 & 2.26 & 0.75 & $\mathrm{NH}_{3}$ umbrella \& $\mathrm{CH}$ bend & $1396 \mathrm{w}$ \\
\hline 48 & 1528.6 & 0.32 & 0.28 & ring ipl $\mathrm{CH}$ dend & $1453 \mathrm{wbr}$ \\
\hline
\end{tabular}




\begin{tabular}{|c|c|c|c|c|c|}
\hline 49 & 1627.3 & 7.22 & 0.75 & ring CC str \& ring ipl bend & $1583 \mathrm{w}$ \\
\hline 50 & 1641.5 & 28.00 & 0.60 & ring CC str \& ring ipl bend & $1605 \mathrm{~m}$ \\
\hline 51 & 1660.9 & 4.69 & 0.73 & $\mathrm{NH}_{3}$ bend & \\
\hline 52 & 1664.3 & 5.84 & 0.74 & $\mathrm{NH}_{3}$ bend & \\
\hline & & & & & $2775 \mathrm{vw}$ \\
\hline 53 & 3008.1 & 117.75 & 0.07 & ${\mathrm{C} 7 \mathrm{H}_{2} \text { sym str }}$ & $2881 \mathrm{w}$ \\
\hline 54 & 3032.8 & 138.69 & 0.02 & $\mathrm{C}_{9} \mathrm{H}_{3}$ sym str & $2937 \mathrm{~m}$ \\
\hline 55 & 3052.1 & 63.89 & 0.67 & ${\mathrm{C} 7 \mathrm{H}_{2} \text { asym str }}$ & \\
\hline 56 & 3084.2 & 42.12 & 0.58 & $\mathrm{C} 8 \mathrm{H} \mathrm{str}$ & \\
\hline 57 & 3103.3 & 49.02 & 0.39 & $\mathrm{C} 8 \mathrm{H} \& \mathrm{C}_{\mathrm{CH}} \mathrm{str}$ & \\
\hline 58 & 3130.6 & 40.09 & 0.57 & ${\mathrm{C} 9 \mathrm{H}_{3} \text { asym str }}$ & $2980 \mathrm{w}$ \\
\hline 59 & 3149.5 & 58.47 & 0.41 & ring $\mathrm{CH}$ str & \\
\hline 60 & 3162.1 & 50.95 & 0.46 & ring $\mathrm{CH}$ str & $3040 \mathrm{wbl}$ \\
\hline 61 & 3181.8 & 94.51 & 0.61 & ring $\mathrm{CH}$ str & $3058 \mathrm{vs}$ \\
\hline 62 & 3191.2 & 64.07 & 0.75 & ring $\mathrm{CH}$ str & $3069 \mathrm{~s}$ \\
\hline 63 & 3201.4 & 266.21 & 0.13 & ring $\mathrm{CH}$ str & \\
\hline 64 & 3394.4 & 116.47 & 0.03 & $\mathrm{NH}_{3}$ sym str & $3168 \mathrm{vw}$ \\
\hline 65 & 3476.3 & 40.21 & 0.65 & $\mathrm{NH}_{3}$ asym str & $3207 \mathrm{vw}$ \\
\hline 66 & 3484.4 & 52.48 & 0.74 & $\mathrm{NH}_{3}$ asym str & $3474 \mathrm{vw}$ \\
\hline
\end{tabular}

* Abbreviations for approximate of vibration: asym $=$ asymmetric, bend $=$ bending, $i p h=$ in phase, $i p l=$ in plane, ooph = out of phase, oopl $=$ out of plane, rot $=$ rotatory oscillation, str $=$ stretching, sym $=$ symmetric, twist $=$ twisting. Codes for band intensity: $\boldsymbol{m}=$ medium, $s=$ strong, $v=$ very, $w=$ weak, $b r=b r o a d$. 
Table 3. Data for calculated and experimental Raman vibrational spectra in $\mathrm{cm}^{-1}$.

\begin{tabular}{|c|c|c|c|}
\hline $\begin{array}{c}\text { Calculated spectral sum of S- } \\
\mathrm{ZN}, \mathrm{S}-\mathrm{ZH} \text { and S-ZC AMPH } \mathrm{Am}^{+} \text {ions } \\
\text { Fig. } 5\end{array}$ & $\begin{array}{l}\text { DL- AMPH }{ }^{+} \text {sulfate in } \\
\text { water } \\
\text { Fig. } 5\end{array}$ & $\begin{array}{c}\text { Calculated spectral sum } \\
\text { of S-ZN, S-ZH and S-ZC } \\
\text { AMP, Fig. } 9\end{array}$ & $\begin{array}{l}\text { AMP drop } \\
\text { Fig. } 9\end{array}$ \\
\hline $240-250 w$ & & $243 \mathrm{~m}, 262 \mathrm{vw}$ & $252 \mathrm{~m}$ \\
\hline $296 \mathrm{w}$ & $315 \mathrm{vw}$ & $309 w$ & $313 w$ \\
\hline $374-422$ vw & $344 \mathrm{vw} \mathrm{br}$ & $327 w, 420 v w$ & \\
\hline $448 \mathrm{vw}$ & $455 \mathrm{w} \mathrm{br}$ & $449 \mathrm{w}$ & $459 w$ \\
\hline$\sim 499 \mathrm{w}$ & $499 \mathrm{vw}$ br & $498 \mathrm{w}, 510 \mathrm{~m}$ & $504 \mathrm{w}$ \\
\hline $604 w$ & $602 \mathrm{vw}$ & $609 w$ & $601 \mathrm{w}$ \\
\hline $635 \mathrm{~m}$ & $624 \mathrm{~m}$ & $636 \mathrm{~m}$ & $623 \mathrm{~m}$ \\
\hline $743 \mathrm{~m}$ & $750 \mathrm{~m}$ & $747 \mathrm{~m}$ & $743 \mathrm{~m}$ \\
\hline $779 \mathrm{w}$ & $790 \mathrm{vw}$ & $796 \mathrm{w}$ & 805 w br sh \\
\hline $824 \mathrm{~s}$ & $821 \mathrm{~s}$ & $815 \mathrm{~m}, 823 \mathrm{w}$ & $823 \mathrm{~m}$ \\
\hline $871 \mathrm{~m}$ & 835 w sh & $848 \mathrm{~m}$ & $835 \mathrm{w}$ br sh \\
\hline $910 \mathrm{w}$ & $897 \mathrm{vw}$ & $900 w, 908 w$ & $881 \mathrm{vw}$ \\
\hline $939 \mathrm{vw}$ & $923 \mathrm{vw}$ & $928 \mathrm{~m}$ & $912 \mathrm{vw}$ \\
\hline $959 w$ & $938 \mathrm{vw}$ & $945 \mathrm{w} \mathrm{br}$ & $941 \mathrm{w} \mathrm{br}$ \\
\hline $970 \mathrm{w}$ & $949 \mathrm{vw}$ & $970 \mathrm{w}$ & 886 w sh \\
\hline $\mathrm{SO}_{4}{ }^{2-}$ not calculated & $981 \mathrm{~s}$ & - & - \\
\hline $1017 \mathrm{vs}$ & 1005 vs & $1017 \mathrm{vs}$ & 1003 vs \\
\hline $1049 \mathrm{~s}$ & $1033 \mathrm{~s}$ & $1060 \mathrm{w} b r, 1050 \mathrm{~s}$ & $1033 \mathrm{~s}$ \\
\hline $1103 \mathrm{vw}$ br & $1108 \mathrm{vw}$ & 1091vw & $1052 \mathrm{vw}$ \\
\hline \multirow[t]{2}{*}{$1133 \mathrm{vw}$} & $1132 \mathrm{vw}$ & $1114 \mathrm{vw}$ & 1133 w, 1110 w, 1095 w \\
\hline & $1161 w$ & $1146 \mathrm{~m}$ & $1155 \mathrm{~m}$ \\
\hline 1190 w sh & $1185 \mathrm{w}$ & $1190 w, 1180 w$ & $1178 \mathrm{~m}$ \\
\hline $1216 \mathrm{~s}$ & $1210 \mathrm{~s}$ & 1219 vs & $1206 s$ \\
\hline $1255 \mathrm{w} \mathrm{br}$ & $1253 \mathrm{vw} \mathrm{br}$ & $1250 \mathrm{vw}, 1230 \mathrm{vw}$ sh, & $1271 \mathrm{vw}$ \\
\hline $1259 \mathrm{~m} \mathrm{br}$ & $1298 \mathrm{vw} \mathrm{br}$ & $1280 \mathrm{vw}, 1306 \mathrm{~m}$ & $1287 \mathrm{vw}$ \\
\hline $\begin{array}{c}1361 \mathrm{w}, 1346 \text { w, } 1334 \mathrm{~m} \text { br, } 1321 \\
\text { w }\end{array}$ & $1325 \mathrm{vw}$ br & $1355 \mathrm{w}$ & $1350 \mathrm{vw}, 1325 \mathrm{vw}$ \\
\hline $1428 \mathrm{w}, 1404 \mathrm{w}, 1387 \mathrm{~m}$ & $1375 \mathrm{~m}$ & 1420 w, 1401 w, 1375 m & $1366 \mathrm{vw}$ \\
\hline $1481 \mathrm{~m} \mathrm{sh}$ & $1447 \mathrm{~m}$ & & $1443 \mathrm{w}$ \\
\hline $1494 \mathrm{~s}$ & $1463 \mathrm{~m}$ & $1526 \mathrm{vw}, 1491 \mathrm{~m}$ & 1493 vw, 1455 w \\
\hline $1622 \mathrm{w}$ & $1586 \mathrm{~m}$ & $1619 \mathrm{~m}$ & $1583 \mathrm{w}$ \\
\hline $1643 \mathrm{~s}$ & $1607 \mathrm{~s}$ & $1644 \mathrm{~s}$ & $1604 \mathrm{~m}$ \\
\hline \multicolumn{4}{|l|}{$1661 \mathrm{~m} \mathrm{sh}$} \\
\hline$-\mathrm{H}_{2} \mathrm{O}$ & $1637 \mathrm{~m} \mathrm{br}$ & - & - \\
\hline
\end{tabular}

*Abbreviations for band intensity: $m=$ medium, $s=$ strong, $s h=$ shoulder, $s p=s h a r p, v=$ very, $w=$ weak, $b r=$ broad. 
Table 4. Titration experiments of DL-Amphetammonium sulfate stock solutions ${ }^{\mathrm{a})}$ and water with $\mathrm{Ba}(\mathrm{OH})_{2}$, precipitating $\mathrm{BaSO}_{4}$ essentially quantitatively.

\begin{tabular}{|c|c|c|c|c|c|c|c|c|c|c|}
\hline & $\begin{array}{c}\text { Solution } \\
(1 \mathrm{~mL})\end{array}$ & $\begin{array}{c}\text { Added } \\
\mathrm{Ba}(\mathrm{OH})_{2} \\
\mathrm{mg}\end{array}$ & $\begin{array}{l}\mathrm{Ba}(\mathrm{OH})_{2} \\
\text { mmoles }\end{array}$ & $\begin{array}{c}\mathrm{pH} \\
\text { measd. }\end{array}$ & Comment & $\begin{array}{c}\text { Calcd. } \\
\text { AMPH }^{+} \\
\text {Molarity }\end{array}$ & $\begin{array}{c}\text { Calcd. } \\
\mathrm{SO}_{4}^{2-} \\
\text { Molarity }\end{array}$ & $\begin{array}{c}\text { Calcd. } \\
\mathrm{Ba}^{2+} \\
\text { Molarity }\end{array}$ & $\begin{array}{c}\text { Calcd. } \\
\mathrm{OH}^{-} \\
\text {Molarity }\end{array}$ & $\begin{array}{c}\text { AMP } \\
\text { Molarity }\end{array}$ \\
\hline A & stock & 0 & 0 & 7 & & 0.1737 & 0.0868 & 0 & 0 & 0 \\
\hline$B^{\text {b) }}$ & stock & 12.6 & 0.0735 & 10.5 & & 0,0267 & 0.0133 & 0 & 0 & 0.1470 \\
\hline C & stock & 25.6 & 0.1494 & 14 & & 0 & 0 & 0.0626 & 0.1251 & 0.1737 \\
\hline D & stock & 51.6 & 0.3011 & 14 & $\begin{array}{l}\text { Solution } \\
\text { cloudy }\end{array}$ & 0 & 0 & 0.2143 & 0.4285 & 0.1737 \\
\hline$E$ & stock & 101.3 & 0.5912 & 14 & $\begin{array}{c}\text { Crystals } \\
\text { observe }\end{array}$ & 0 & 0 & 0.5044 & 1.0087 & 0.1737 \\
\hline$F$ & Water & 15.6 & 0.0910 & 14 & & 0 & 0 & 0.0910 & 0.182 & 0 \\
\hline
\end{tabular}

a) $32 \mathrm{mg} / \mathrm{mL}$.

b) The pKa acidity constant of the amphetammonium-amphetamine acid-base pair calculates to 9.76 from experiment $B$ (by use of the Henderson-Hasselbalck equation: $-p K a=p H-l o g$ $\left.[\mathrm{AMP}] /\left[\mathrm{AMPH}^{+}\right]\right)$, in good agreement with the 9.8 value often cited in the literature. 


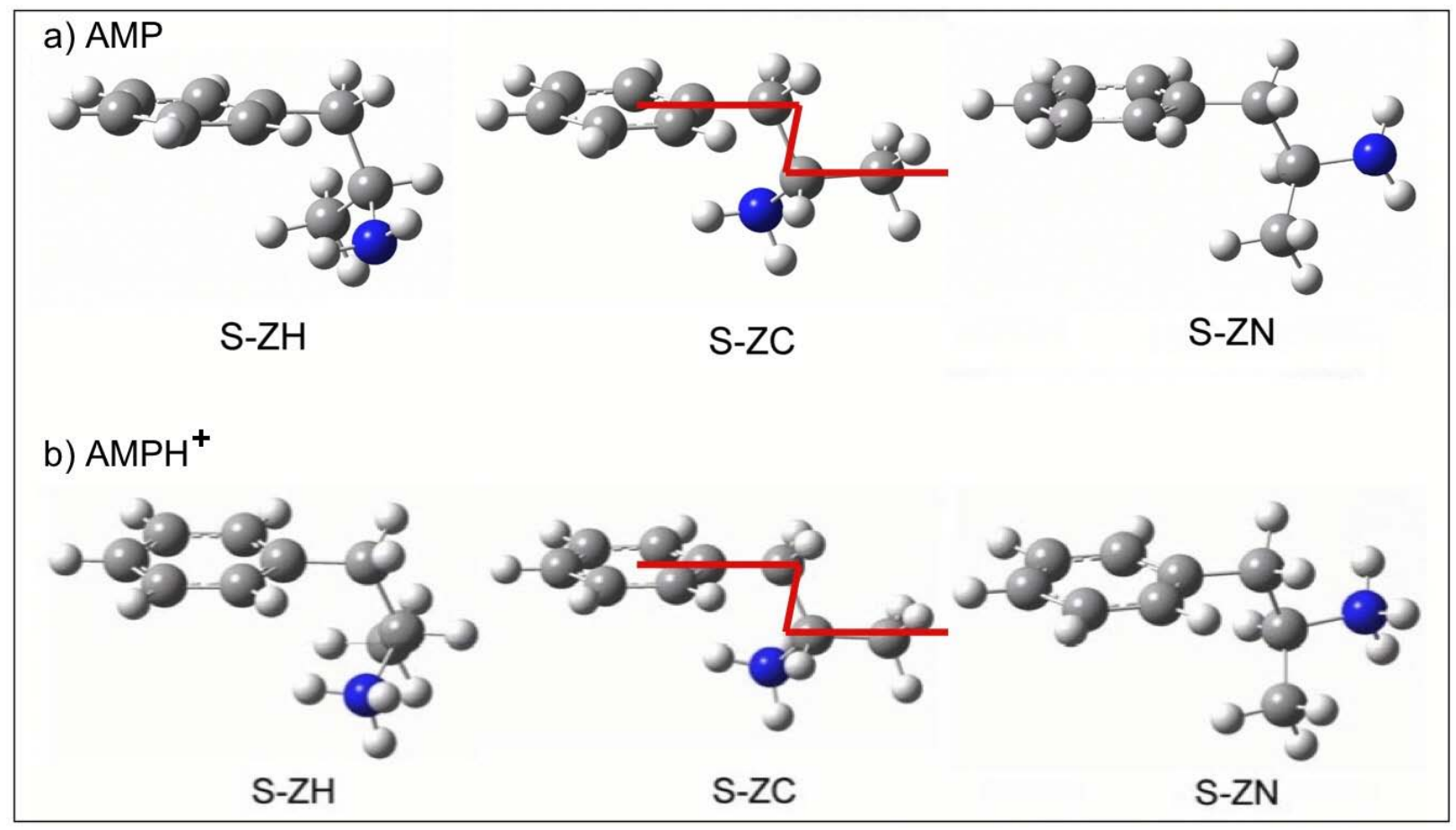

Fig. 1. (a) The S-amphetamine molecule shown in three different conformational geometries, here called S-ZH, S-ZC and S-ZN. The stereoisomer specification of $S$ (or its mirror image R) comes from the sequence rule that gives the four different groups attached to the asymmetric carbon (C8) priority according to atom number and mass (priorities: $\mathrm{H}=\mathrm{low}, \mathrm{CH}_{3}, \mathrm{C}_{7} \mathrm{H}_{7}, \mathrm{NH}_{2}=h i g h e s t$ ). When looking at $\mathrm{C} 8$ from the side opposite of the lowest priority group $(\mathrm{H})$, the remaining groups - to give $S$ - must proceed in clockwise order when stepping up in priority (most clearly seen for $S-Z N)$. The next designation, e.g. ZC, is introduced to give a short specification of the rotational geometry around C7-C8, i.e. for the case of ZC it specifies that the bond to the methyl group (C) is parallel to the long axis of the benzyl group. (b) The S-amphetamine-H ${ }^{+}$ion shown in its analogous conformations $S-Z H, S-Z C$ and $S-Z N$. The specification $S$ (or its mirror image $R$ ) of the asymmetric carbon (C8) follows the same sequence rule as in (a) (priorities: $\mathrm{NH}_{3}^{+}=\mathrm{high}_{\mathrm{g}} \mathrm{C}_{7} \mathrm{H}_{7}$, $\mathrm{CH}_{3}, \mathrm{H}=$ low). 


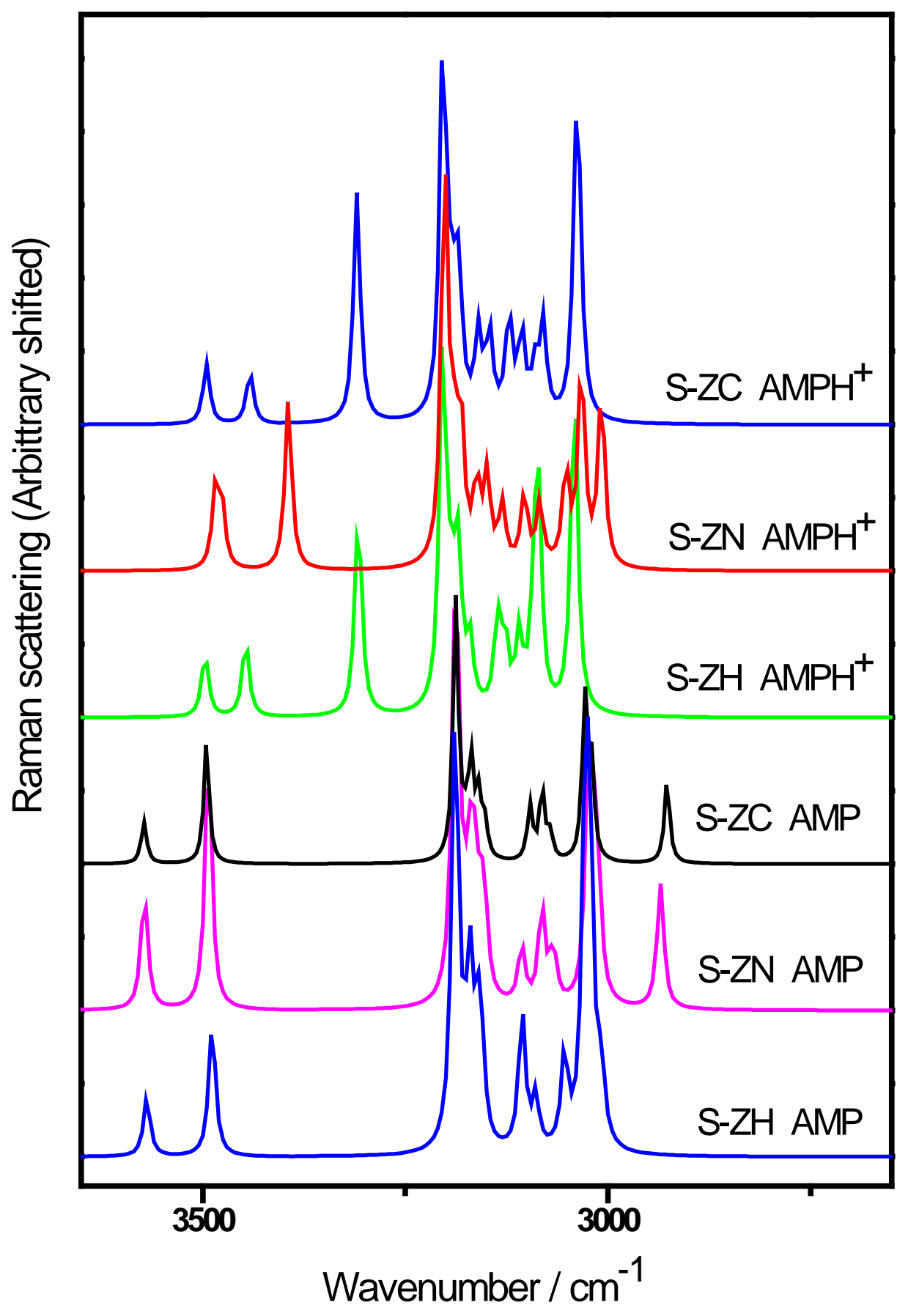

FIG. 2. Calculated Raman spectra in the high wavenumber-range $\left(3650-2650 \mathrm{~cm}^{-1}\right)$ of the Samphetamine $-\mathrm{H}^{+}$ion and the $\mathrm{S}$-amphetamine molecule in their three different conformational geometries S-ZC, S-ZN and S-ZH. 


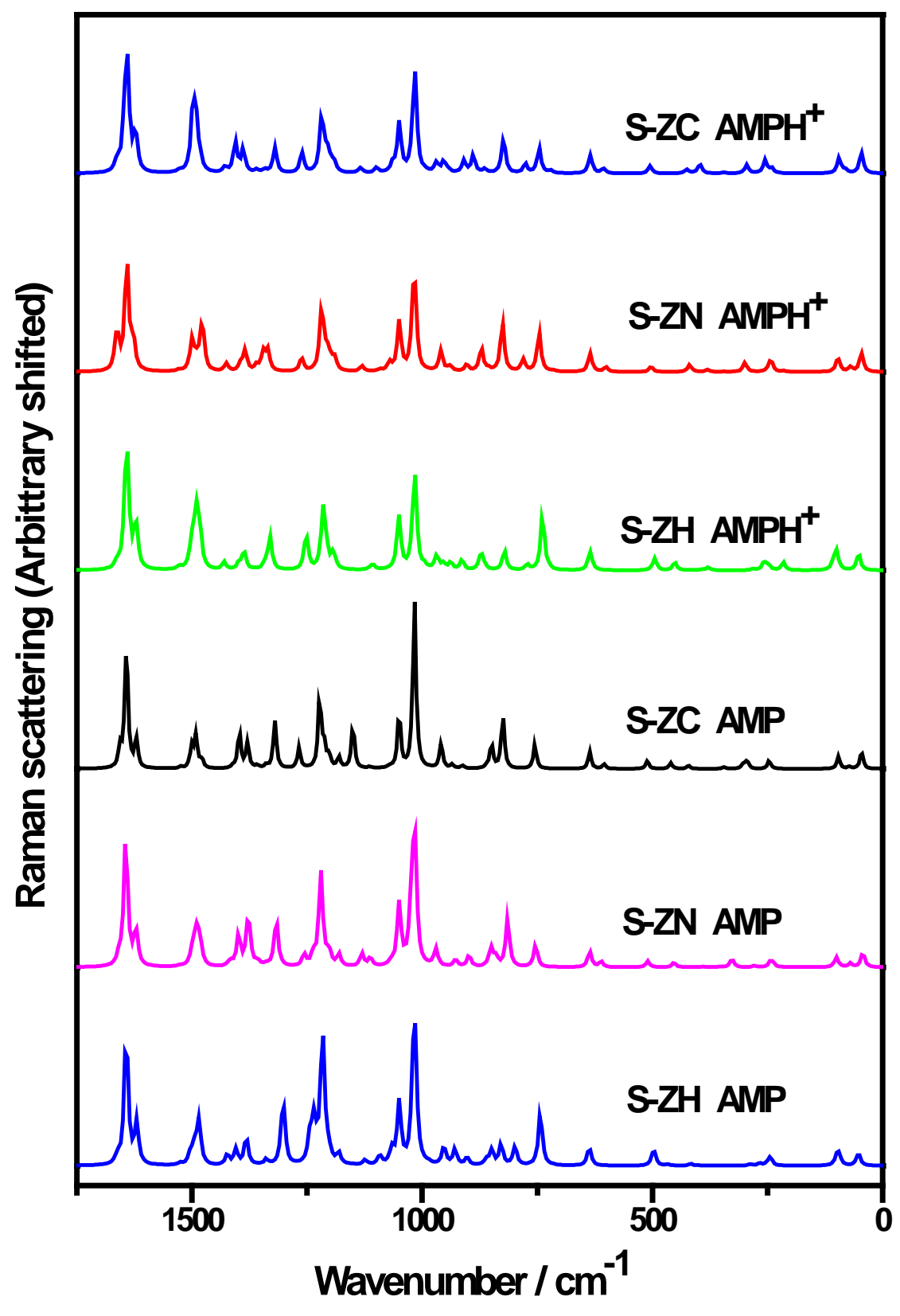

FIG. 3. Calculated Raman spectra in the low wavenumber-range $\left(1750-0 \mathrm{~cm}^{-1}\right)$ of the Samphetamine- $\mathrm{H}^{+}$ion and the $S$-amphetamine molecule in their three different conformational geometries S-ZC, S-ZN and S-ZH. 


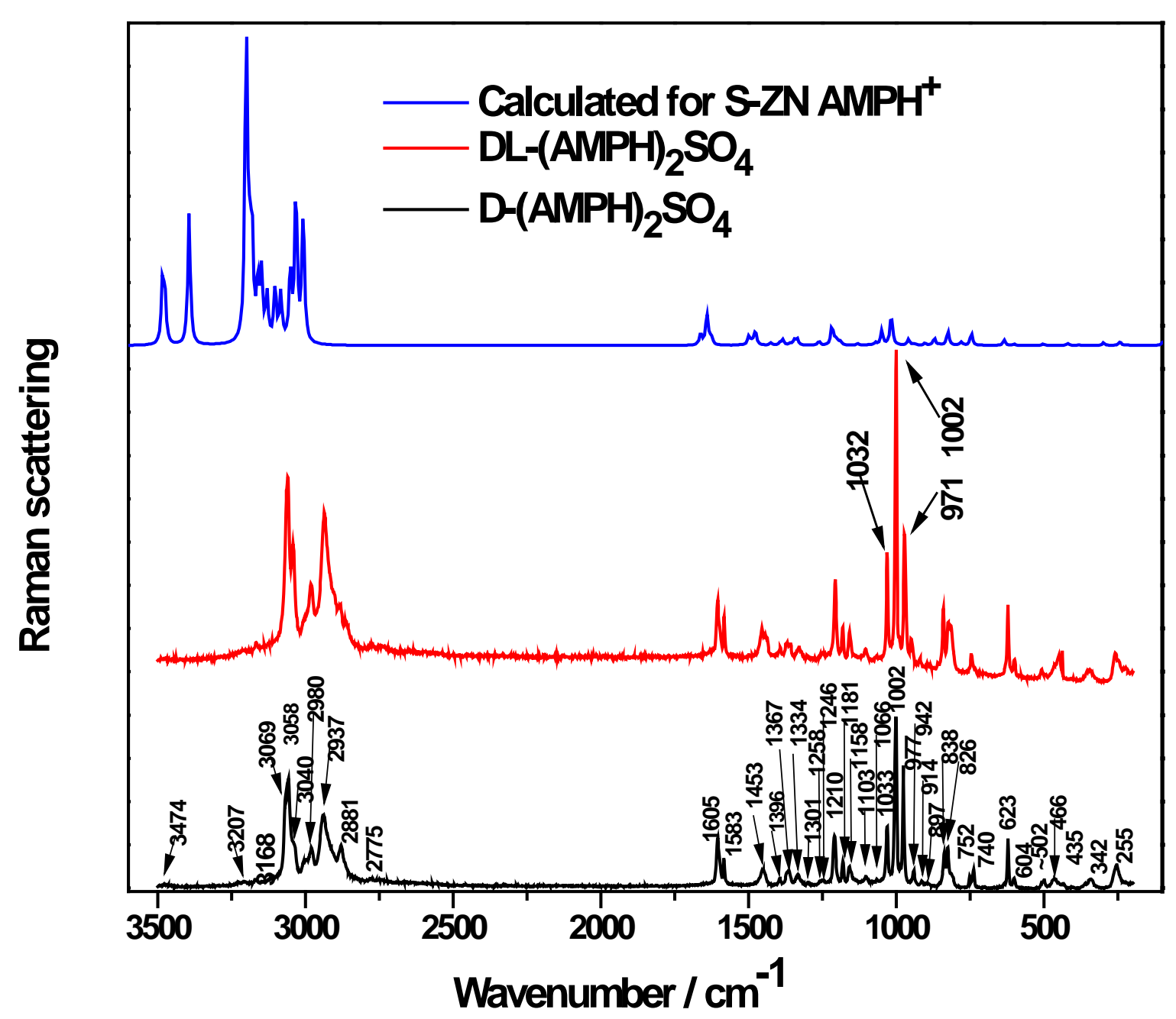

Fig. 4. Raman spectra of solid DL-and di-D-amphetammonium sulfates, obtained on the LABRAM instrument with $514.5 \mathrm{~nm}$ laser light, $11 \mathrm{~mW}$ through a 10X objective, acquisition times being $1 \times 10$ sec. For comparison the calculated spectrum for the $\mathrm{AMPH}^{+}$ion in S-ZN conformation is shown. 


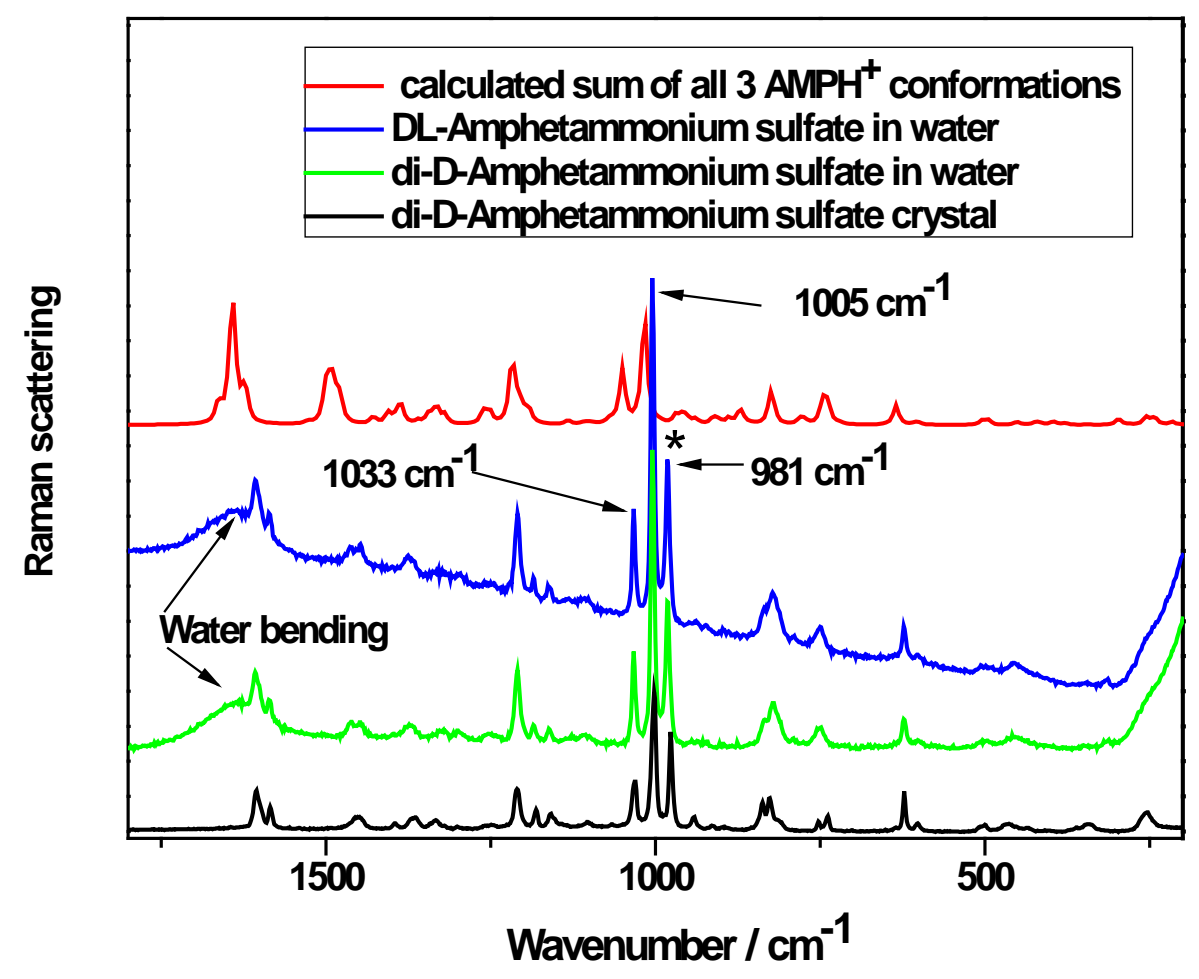

Fig. 5. Comparison of Raman spectra of solid di-D- and aqueous solutions (ca. $0.08 \mathrm{~mol} / \mathrm{L}$ in water), of DL-and di-D-amphetammonium sulfate obtained at $25^{\circ} \mathrm{C}$ on the LABRAM Raman instrument and with $514.5 \mathrm{~nm}$ laser light, $11 \mathrm{~mW}$ through a 10X objective. Acquisition time for the solutions $1 \times 20 \mathrm{sec}$, for the solid $1 \times 10 \mathrm{sec}$. For comparison a sum of calculated $\mathrm{AMPH}^{+}$model spectra is shown. The asterisk is labelling the $\mathrm{SO}_{4}{ }^{2-}$ sym stretching. 


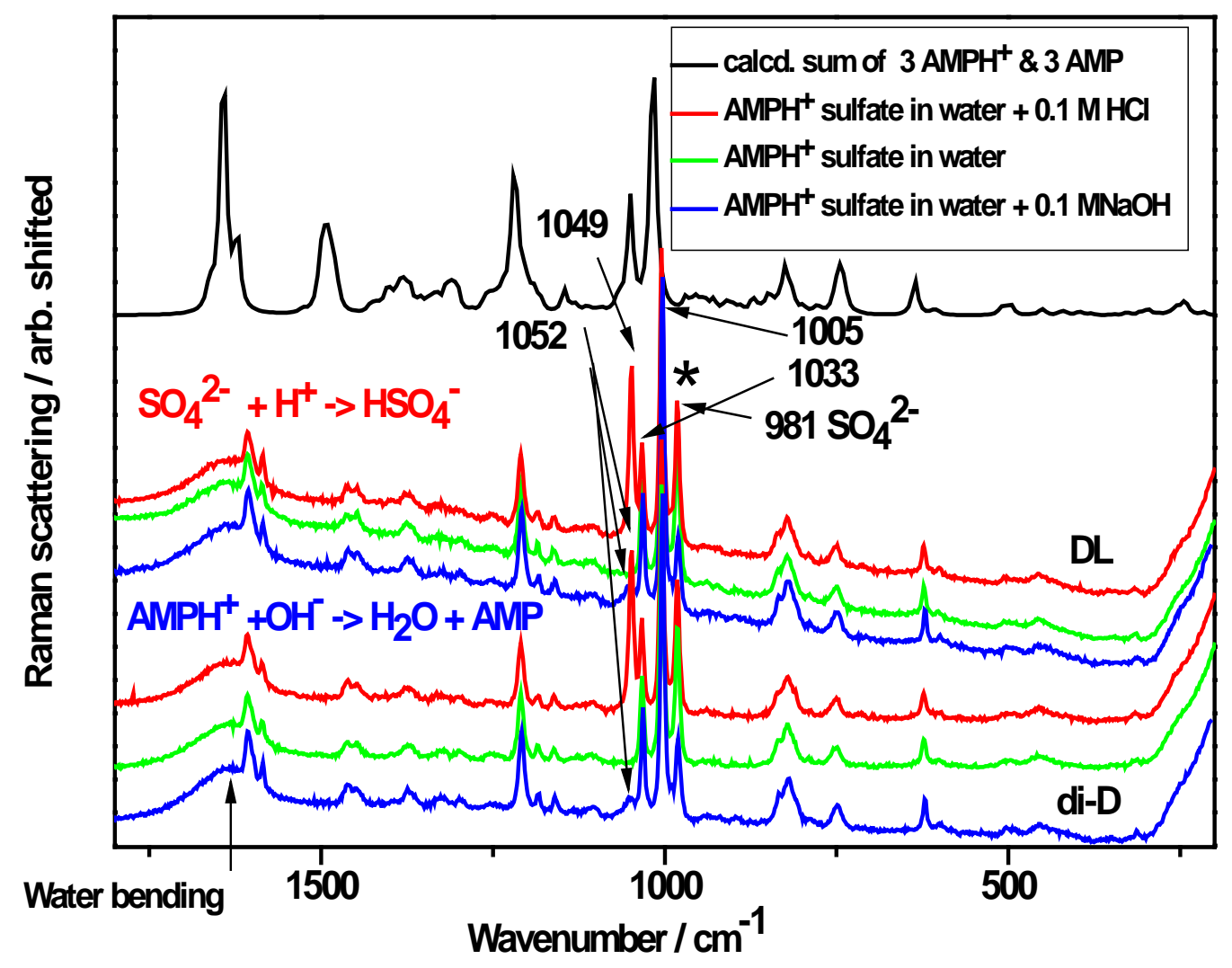

FIG. 6. Raman spectra of $30 \mathrm{mg} / \mathrm{mL}$ aqueous solutions of $D L$ - and di-D-amphetammonium sulfate, ca. $30.4 \mathrm{mg}$ in $1 \mathrm{~mL}$ water obtained at $25^{\circ} \mathrm{C}$ with $514.5 \mathrm{~nm}$ laser light, $11 \mathrm{~mW}$ through a $10 X$ objective, on the LABRAM instrument. Acquisition time was $1 \times 20$ sec. For comparison, the sum of all six calculated AMP and AMPH+ model spectra is included. An asterisk is labelling the $\mathrm{SO}_{4}{ }^{2-}$ sym stretching. To make the solutions acidic or basic $0.1 \mathrm{M} \mathrm{HCl}$ or $\mathrm{NaOH}$ was used. 


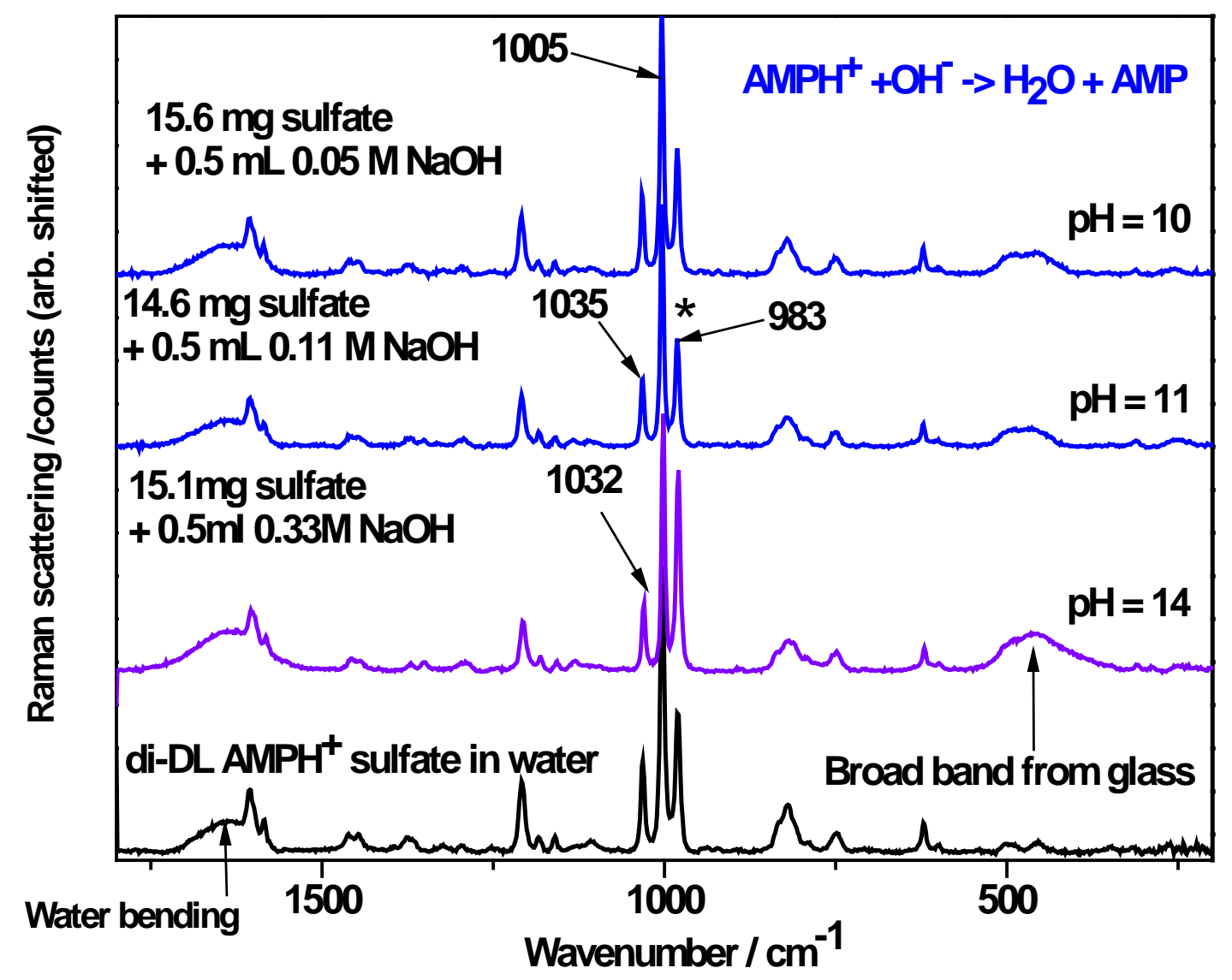

FIG. 7. Raman spectra versus the relative amounts of $D L-A M P H^{+}$sulfate and $\mathrm{NaOH}$ in aqueous solutions. The $\mathrm{pH}$ acidity is given. Raman conditions: LABRAM, $514.5 \mathrm{~nm}, 11 \mathrm{~mW}$ through a $10 X$ objective, neutral density filter fully open, hole 600, slits 100, 6 ×30 sec. 


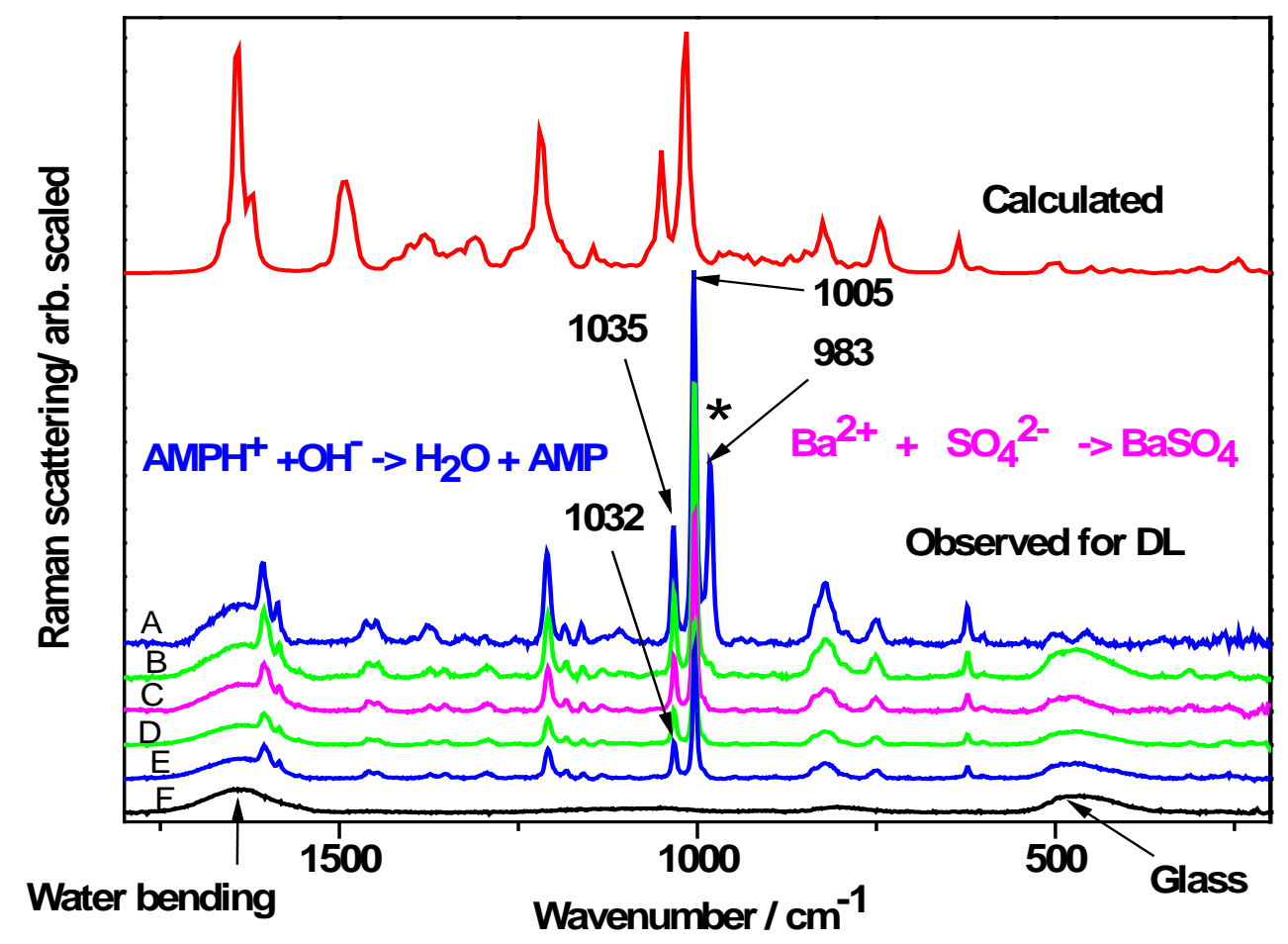

FIG. 8. Experimental titration of solutions of aqueous DL-amphetammonium sulfate stock solutions with barium hydroxide $\left(25^{\circ} \mathrm{C}\right)$. Spectra shown of solutions as given in Table 4: $1 \mathrm{~mL}$ of stock solution (at $32 \mathrm{mg} / \mathrm{mL}$ ) after addition of respectively: $0 \mathrm{mg}(A), 12.6 \mathrm{mg}(B), 25.6 \mathrm{mg}$ (C), 51.6 $\mathrm{mg}(\mathrm{D})$, and $101.3 \mathrm{mg}(\mathrm{E})$ of $\mathrm{Ba}(\mathrm{OH})_{2}$. The spectrum of a solution of $15.6 \mathrm{mg}$ barium hydroxide in $1.0 \mathrm{~mL}$ of water is given as (F). Conditions: LABRAM instrument, with $514.5 \mathrm{~nm}$ laser light, $11 \mathrm{~mW}$ through a 10X objective, neutral density filter fully open, hole $600 \mathrm{~nm}$, slits $100 \mathrm{~nm}$, acquisition time $6 \times 30 \mathrm{~s}$. For comparison a spectrum of the sum of calculated $\mathrm{AMPH}^{+}$model spectra is also shown. An asterisk is labelling the $\mathrm{SO}_{4}{ }^{2-}$ symmetrical stretching. 


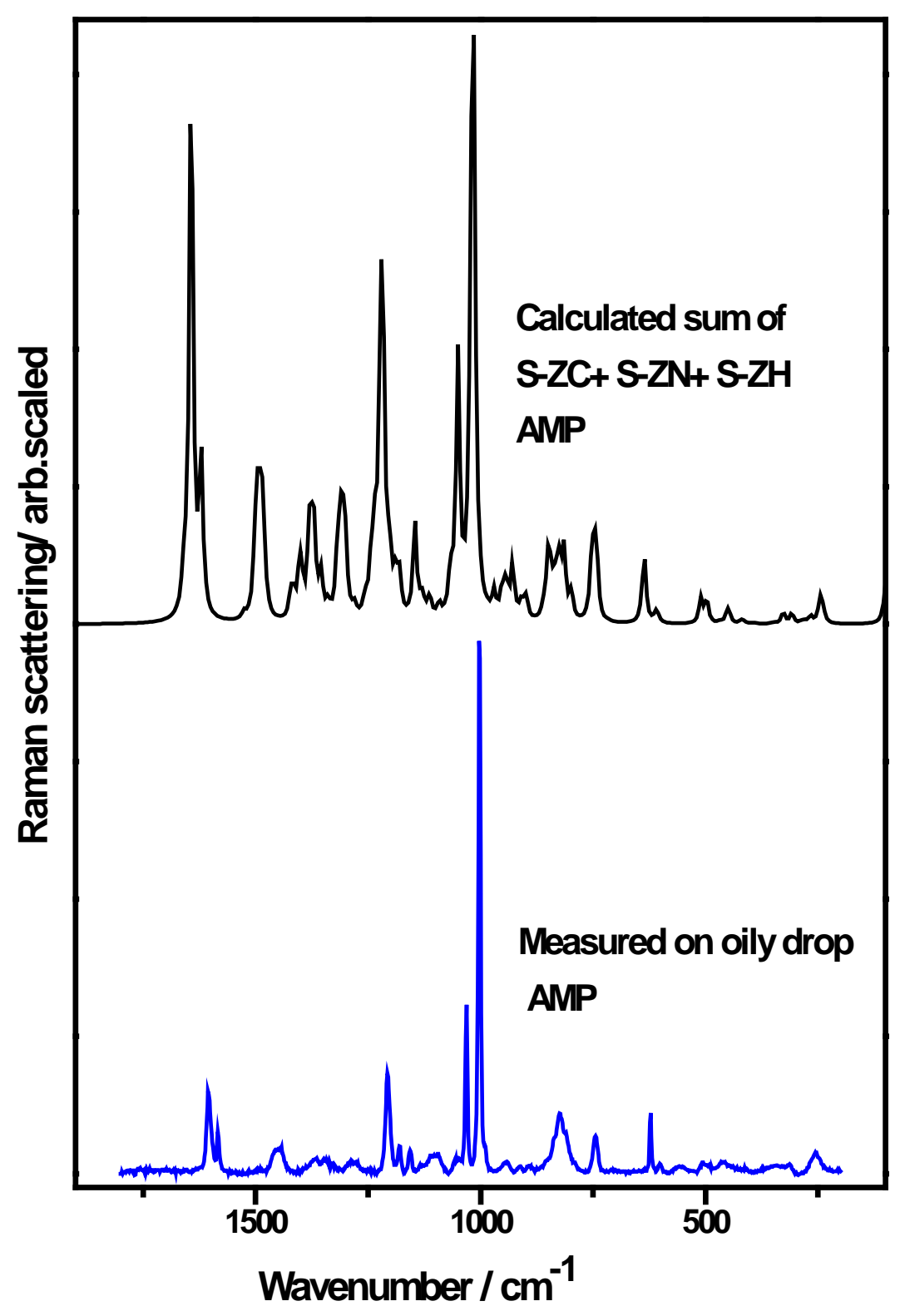

Fig. 9. Raman spectrum from an oily droplet separated from a $D L-A M P H^{+}$sulfate solution to which enough $\mathrm{NaOH}$ has been added. The spectrum shows that the oil consisted of AMP. The sum of the three calculated AMP conformations is given for comparison. Experimental Conditions: LABRAM instrument with $514.5 \mathrm{~nm}$ laser light, $11 \mathrm{~mW}$ through a 10X objective, neutral density filter half open, hole $600 \mathrm{~nm}$, slits $100 \mathrm{~nm}$, acquisition time 6x10 sec. 


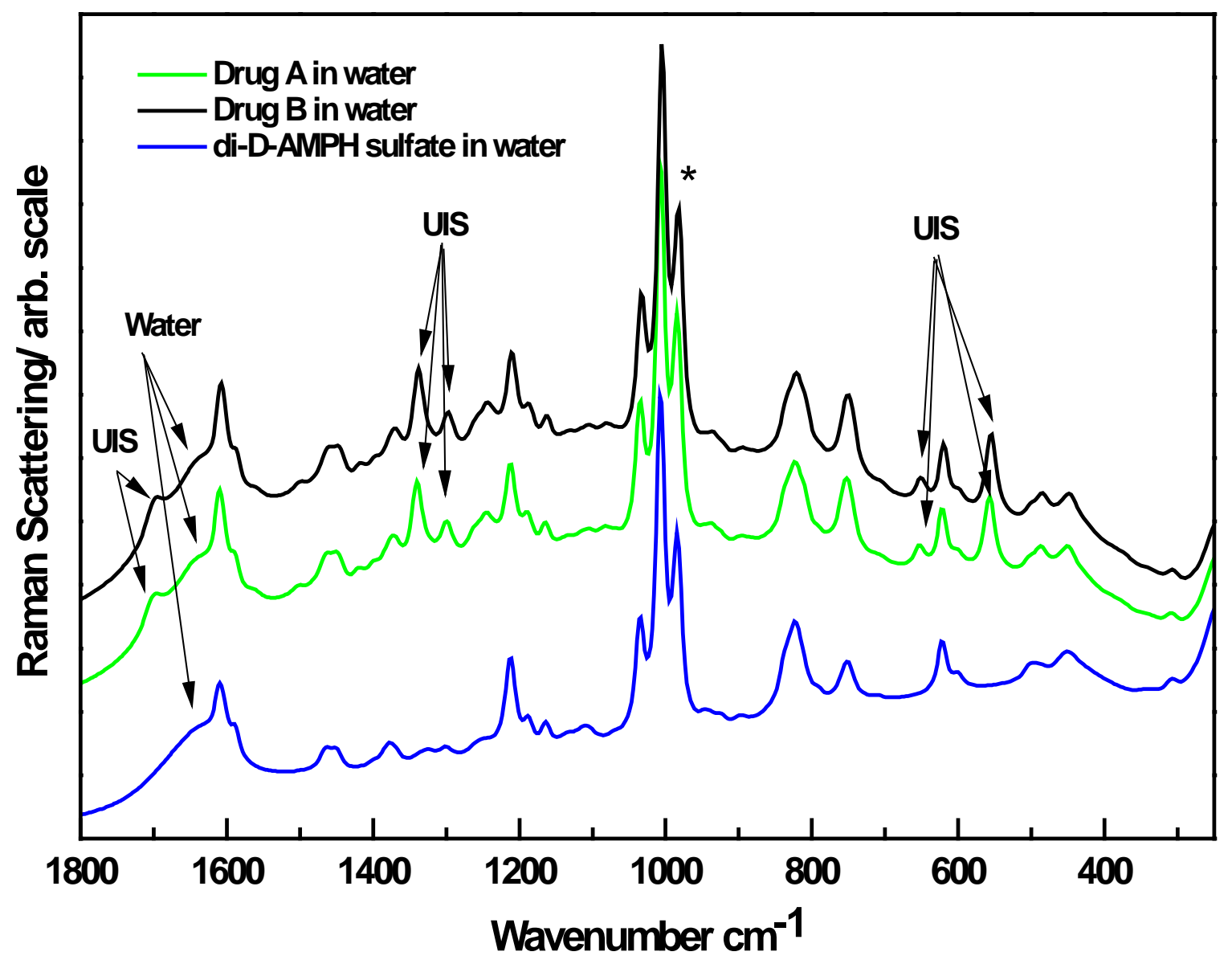

FIG. 10. Raman spectra of solutions of street drug powders, dissolved in water and filtered. Drug A solution is of a concentration of $60 \mathrm{mg} / \mathrm{mL}$, drug $B$ of $64 \mathrm{mg} / \mathrm{mL}$. Also shown is the spectrum of di-D-amphetammonium sulfate at a concentration of $\approx 0.08 \mathrm{M}(\mathrm{AM} P H)_{2} \mathrm{SO}_{4}$, or $0.16 \mathrm{MAMPH}$. UIS $=$ Unidentified substance. The sulfate stretching band is indicated with an asterisk. 


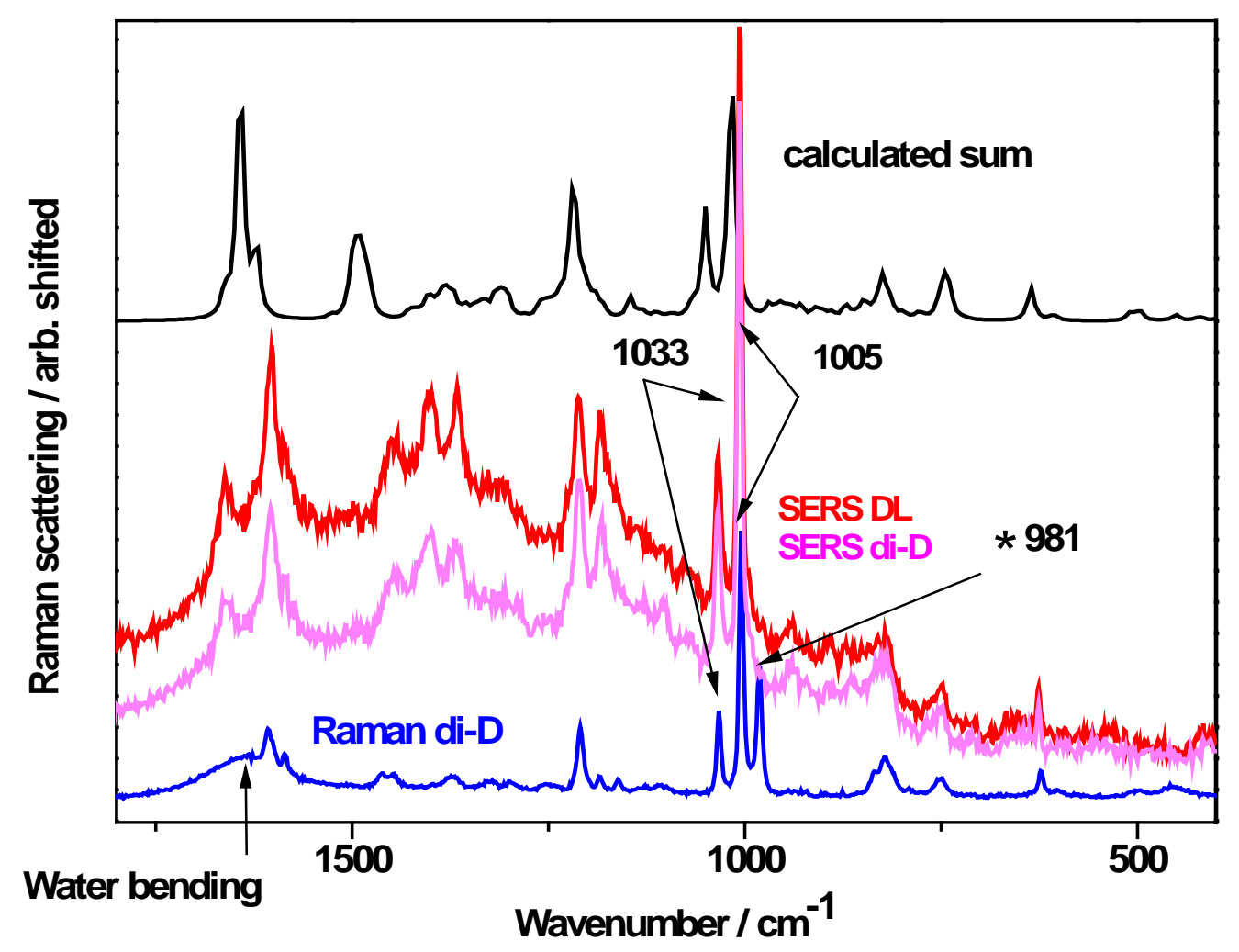

Fig. 11. SERS spectra obtained of $D L-A M P H^{+}$sulfate and di-D-AMPH ${ }^{+}$sulfate in dilute solutions (concentrations of $2.6 \mathrm{mM} \mathrm{AMPH}^{+}$). Conditions: LABRAM, $514.5 \mathrm{~nm}$ excitation, $11 \mathrm{~mW}$ through a $10 X$ objective, acquision times $1 \times 10 \mathrm{sec}$. For reference the calculated sum of the three $A M P H^{+}$ conformations is shown at the top and the normal Raman spectrum of a $0.08 \mathrm{M}(\mathrm{AMPH})_{2} \mathrm{SO}_{4}$ solution at the bottom. 


\section{Appendix}

Supplementary Figure S1. Calculated Raman spectra.

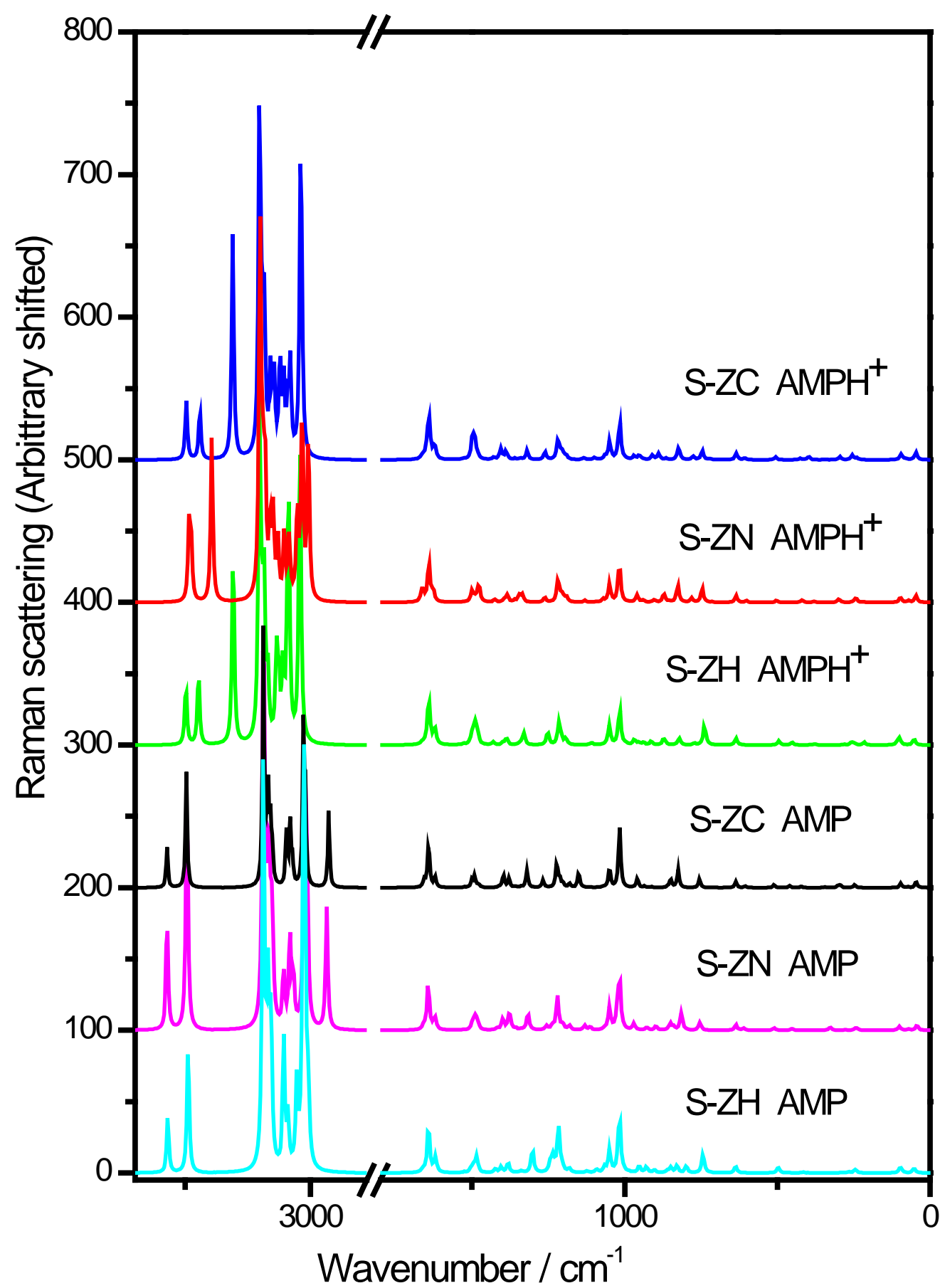


Supplementary Figure S2. Calculated IR emission spectra.

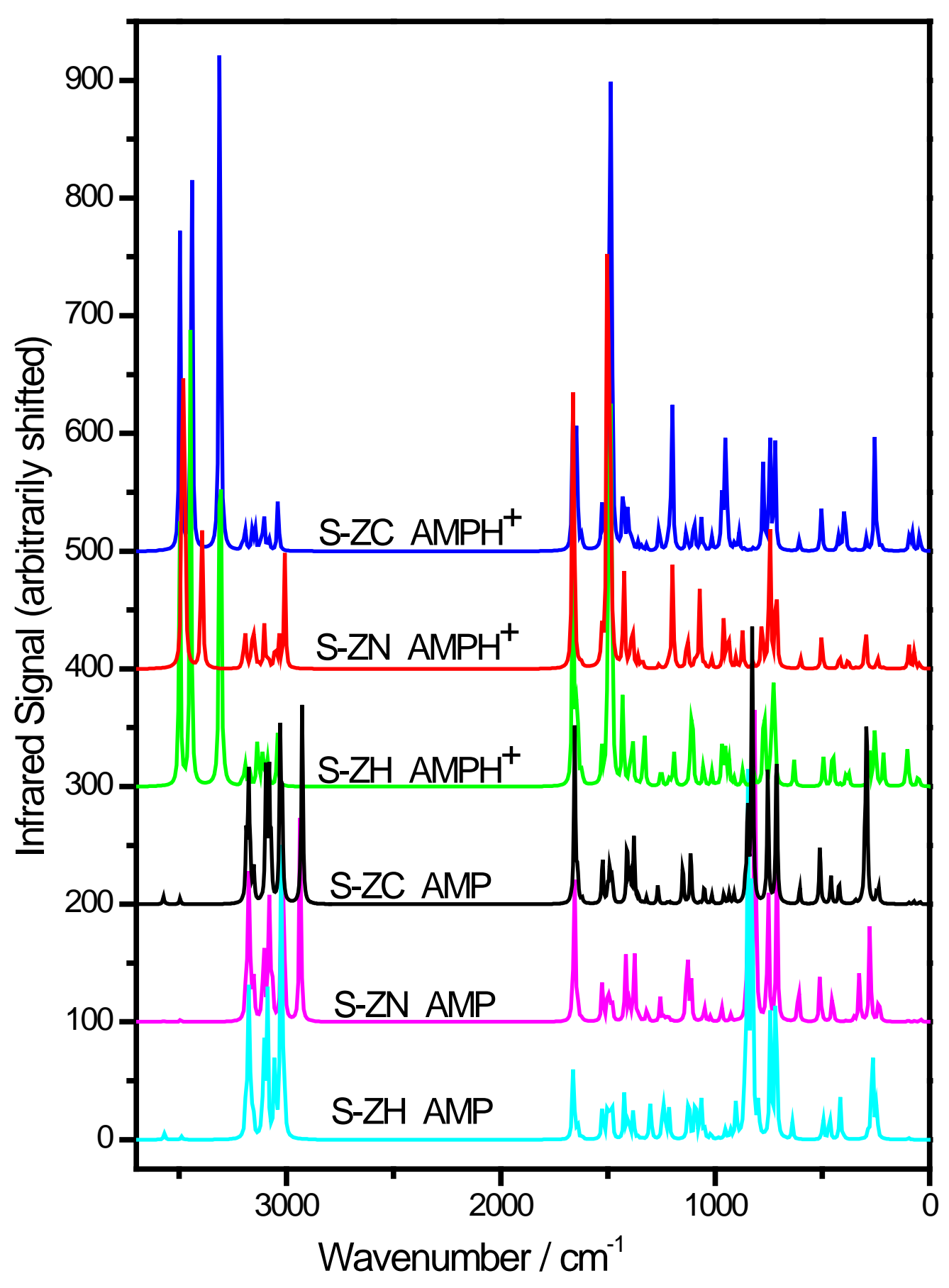

